\title{
Operating conditions of an open and direct solar thermal Brayton cycle with optimised cavity receiver and recuperator
}

\author{
W.G. le Roux, T. Bello-Ochende* and J.P. Meyer \\ Department of Mechanical and Aeronautical Engineering, University of Pretoria, Pretoria, \\ Private Bag X20, Hatfield, 0028, South Africa.
}

\begin{abstract}
The small-scale open and direct solar thermal Brayton cycle with recuperator has several advantages, including low cost, low operation and maintenance costs and it is highly recommended. The main disadvantages of this cycle are the pressure losses in the recuperator and receiver, turbomachine efficiencies and recuperator effectiveness, which limit the net power output of such a system. The irreversibilities of the solar thermal Brayton cycle are mainly due to heat transfer across a finite temperature difference and fluid friction. In this paper, thermodynamic optimisation is applied to concentrate on these disadvantages in order to optimise the receiver and recuperator and to maximise the net power output of the system at various steady-state conditions, limited to various constraints. The effects of wind, receiver inclination, rim angle, atmospheric temperature and pressure, recuperator height, solar irradiance and concentration ratio on the optimum geometries and performance were investigated. The dynamic trajectory optimisation method was applied. Operating points of a standard micro-turbine operating at its highest compressor efficiency and a parabolic dish concentrator diameter of 16 metres were considered. The optimum geometries, minimum irreversibility rates and maximum receiver surface temperatures of the optimised systems are shown. For an environment with specific conditions and constraints, there exists an optimum receiver and recuperator geometry so that the system produces maximum net power output.
\end{abstract}

Keywords: solar; Brayton; optimisation; geometry; receiver; recuperator

\section{Introduction}

*Corresponding author. Tel.: +2712 420 3105; fax: +2712 362 5124. E-mail address: tunde.bello-ochende@up.ac.za 
Concentrated solar power systems use the concentrated power of the sun as a heat source to generate mechanical power. The Brayton cycle is definitely worth studying when comparing its efficiency with that of other power cycles [1]. Emphasis may shortly shift to solarised Brayton micro-turbines from Dish-Stirling technology due to high Stirling engine costs [2]. When a recuperator is used, the Brayton cycle has very high efficiency at low pressure ratios. The main disadvantages of a solar thermal Brayton cycle are the pressure losses in the recuperator and receiver, turbomachine efficiencies and recuperator effectiveness [3], which limit the net power output of such a system. To obtain the maximum net power output, a combined effort of heat transfer, fluid mechanics and thermodynamic thought is required. The method of entropy generation minimisation combines these thoughts [4].

The irreversibilities of the recuperative solar thermal Brayton cycle are mainly due to heat transfer across a finite temperature difference and fluid friction. Various authors have emphasised the importance of the optimisation of the global performance of a system, by minimising the total irreversibility rate from all the different components or processes of the system by sizing the components accordingly [5-11]. The geometries of the receiver and recuperator can be optimised in such a way that the total entropy generation rate is minimised to allow maximum net power output at any steady-state condition.

Entropy generation minimisation has been used in various internal flow optimisation studies such as: the optimum tube diameter for a tube [5,7]; the optimal aspect ratio for singlephase, fully developed, laminar and turbulent flow with constant heat flux [12]; and the optimum channel geometries with constant wall temperature or constant heat flux [10-11]. Entropy generation and its minimisation have been expressed for numerous heat exchangers and heat transfer surfaces: counterflow and nearly-ideal heat exchanger neglecting fluid friction [13], tubular heat exchangers [14,15], heat exchangers restricted to perfect gas flows [16], balanced cross-flow recuperative plate-type heat exchangers with unmixed fluids [17]; and a parallel-plate ideal gas counterflow heat exchanger [8]. The $\varepsilon-N T U$ method, based on the second law of thermodynamics, can be used to get the outlet temperatures and the total heat transfer from the hot fluid to the cold fluid in a heat exchanger $[8,16,17]$.

When mounting a black solar receiver at the focus of a parabolic dish concentrator, it can be sized such that it absorbs the maximum heat [3]. Convection losses can be drastically reduced with the use of a cavity receiver. Different types of cavity receivers have been 
compared [18-20]. The modified cavity receiver is suggested by Sendhil Kumar and Reddy [20] since it experiences lower convection heat losses. For the modified cavity receiver, a numerical investigation of natural convection heat loss is available [21], the contribution of radiation losses is considered [22] and an improved model for natural convection heat loss is available [23].

Exergy analysis has been applied in various power studies [24-26]. Exergetic analysis for a regenerative Brayton cycle with isothermal heat addition and isentropic compressor and turbine [27] is available. Thermodynamic analyses and optimisation of a recompression $\mathrm{N}_{2} \mathrm{O}$ Brayton power cycle have been done [28]. The performance of a regenerative Brayton heat engine has been studied by focusing on the minimisation of irreversibilities [29].

With an exergy analysis of the open and direct solar thermal Brayton cycle, the geometries of a modified cavity receiver [20-23] and counterflow plate-type recuperator [30] have been optimised [31] for various configurations of micro-turbines and concentrator diameters, so that the system produces maximum net power output. In this paper, the operating conditions of a single optimised configuration are given at various steady-state conditions. The effects of environmental parameters (geometry and environment conditions) on the optimum operating conditions are investigated.

\section{Model}

\subsection{The control volume}

The open and direct solar thermal Brayton cycle with recuperator is shown schematically in Fig. 1. A parabolic concentrator provides the solar heat for the cavity receiver. For a specific concentrator with constant diameter, focal length and rim angle, the rate of steady-state intercepted heat by the cavity receiver, $\dot{Q}^{*}$, depends on the cavity receiver aperture (which depends on the geometries of the cavity receiver). $\dot{Q}^{*}$ can be regarded as the intercepted heat rate at the receiver, after the irreversibility rates due to scattering from the concentrator and the transformation of radiation at the receiver have been deducted. $\dot{W}_{n e t}$ is the net power output of the system. 


\subsection{Solar receiver model}

The modified cavity receiver suggested by Reddy and Sendhil Kumar [23] is considered in the analysis and is shown in Fig. 2. The receiver inner surface is made up of a closely wound copper tube with diameter, $D_{r e c}$, through which the working fluid travels. The receiver tube with length, $L_{r e c}$, constructs the cavity receiver and its aperture. The receiver diameter, $D_{s p h}$, is a multiple of the aperture diameter of the receiver, $d$. In this analysis, this multiple is fixed. An area ratio of $A_{w} / A_{a}=8$ is recommended [23] as it was found to be the ratio that gives the minimum heat loss from the cavity receiver. The convection heat loss takes place through the receiver aperture. Since the surface area of a sphere is $\pi D^{2}$, the diameter of the spherical receiver can be calculated as

$D_{s p h}=2 \sqrt{\left(A_{w}+A_{a}\right) / 3 \pi}$

Due to the area ratio constraint, the receiver diameter is a function of the receiver aperture diameter,

$D_{s p h}=\sqrt{3} d$

The receiver aperture diameter can be calculated using Eq. (3) since $A_{w}=D_{\text {rec }} L_{\text {rec }}$.

$d=\sqrt{D_{r e c} L_{r e c} / 2 \pi}$

According to Reddy and Sendhil Kumar [23], for $A_{w} / A_{a}=8$, the Nusselt number for natural convection heat loss based on receiver diameter for a 3-D receiver model can be calculated as a function of the inclination angle of the receiver,

$$
N u_{D}=h_{\text {conv }} D_{s p h} / k=0.698 G r_{D}{ }^{0.209}(1+\cos \beta)^{0.968}\left(T_{w} / T_{0}\right)^{-0.317}\left(d / D_{s p h}\right)^{0.425}
$$


For $A_{w} / A_{a}=8$, the ratio of radiation heat loss to convection heat loss is a function of receiver inclination and varies between approximately 0.9 and 1.45 [22]. For the heat loss rate from the cavity receiver, it is therefore assumed that $\dot{Q}_{\text {loss, rad }} \approx \dot{Q}_{\text {loss, conv }}$ or $\dot{Q}_{\text {loss }} \approx 2 \dot{Q}_{\text {loss,conv }}$. The total rate of heat loss due to convection and radiation, is approximated as

$\dot{Q}_{\text {loss }} \approx 1.396 G r_{D}^{0.209}(1+\cos \beta)^{0.968}\left(T_{w} / T_{0}\right)^{-0.317}\left(d / D_{s p h}\right)^{0.425}\left(k A_{a} / D_{s p h}\right)\left(T_{w}-T_{0}\right)$

\subsection{Determination of net absorbed power}

In practice, reflected rays from a solar concentrator form an image of finite size centred around its focal point. This is due to the sun's rays not being truly parallel and due to concentrator errors. The larger the receiver aperture diameter, the larger the rate of heat intercepted by the receiver, $\dot{Q}^{*}$. Also, the larger the aperture diameter, the larger the heat loss

rate, $\dot{Q}_{\text {loss }}$, due to convection and radiation in Eq. (5). The net rate of absorbed heat, $\dot{Q}_{n e t}$, is the intercepted heat rate minus the total heat loss rate.

The sizing algorithm of Stine and Harrigan [3] is applied to determine $\dot{Q}^{*}$ for a specific aperture diameter. Starting at a rim angle of $0^{\circ}$ through to an angle of $\varphi_{\text {rim }}$, in increments of $1^{\circ}$, the rate of intercepted solar energy per segment of concentrator area is computed. From this, the net absorbed heat rate as a function of the receiver aperture diameter can also be computed. Fig. 3 shows the relation between $\dot{Q}_{n e t}$ and the receiver aperture diameter for a number of different concentrator diameters. Note that Fig. 3 was generated by using a parabolic concentrator error of $0.0067 \mathrm{rad}$ [3], concentrator specular reflectivity of 0.93 and the default values for the surrounding temperature, wind, rim angle, solar irradiance and inclination as shown in Table 1.

The shadow of the receiver and its insulation is also accounted for when calculating the intercepted power. The rate of conduction heat loss is assumed $10 \%$ of the sum of the radiation and convection heat loss rates. Each curve in Fig. 3 can be numerically approximated 
with Eq. (6) using the discrete least-squares approximation method [32], where $y_{i}$ is a set of constants used to describe the function.

$$
\dot{Q}_{n e t}=\sum_{i=0}^{10} y_{i} d^{i}
$$

\subsection{Recuperator model}

A counterflow plate-type recuperator was used as shown in Fig. 4. The channels with hydraulic diameter, $D_{h, r e g}$, length, $L_{r e g}$, and aspect ratio, $a / b_{\text {reg }}$ are shown. The number of flow channels in the recuperator, $n$, depends on the recuperator height, $H$, channel height, $b$, and thickness of the channel-separating surface, $t$, and can be written as a function of the channel aspect ratio,

$$
n=H /(t+b)=\frac{H}{t+D_{h, \text { reg }}\left((a / b)_{\text {reg }}+1\right) /\left(2(a / b)_{\text {reg }}\right)}
$$

Eq. (8) gives the mass flow rate per channel.

$$
\dot{m}_{c}=2 \dot{m} / n
$$

The surface area, $A_{s}$, for a channel as a function of the channel aspect ratio is

$$
A_{s}=2(a+b) L_{r e g}=D_{h, r e g} L_{r e g}\left((a / b)_{r e g}+1\right)\left(1+(a / b)_{r e g}^{-1}\right)
$$

The Reynolds number for a flow channel is

$$
\operatorname{Re}=\dot{m}_{c} D_{h, r e g}(a / b)_{r e g} / \mu a^{2}
$$


Using the definition of the hydraulic diameter and Eq. (10), the Reynolds number can be calculated with

$$
\operatorname{Re}=\frac{4(a / b)_{\text {reg }} \dot{m}_{c}}{\mu D_{h, r e g}\left((a / b)_{\text {reg }}+1\right)^{2}}
$$

Heat exchanger irreversibilities can be reduced by slowing down the movement of fluid through a heat exchanger [4]. Small Reynolds numbers can thus be expected for the optimised recuperator channels and the Gnielinski equation [33] can be used to determine the Nusselt number,

$$
N u=(\operatorname{Pr}(\operatorname{Re}-1000)(f / 8)) /\left(1+12.7(f / 8)^{0.5}\left(\operatorname{Pr}^{2 / 3}-1\right)\right)
$$

The Petukhov equation [34] is used to calculate the friction factor,

$$
f=(0.79 \ln \mathrm{Re}-1.64)^{-2}
$$

With the use of the friction factor, Reynolds number and the definition of the pressure drop [35], the pressure drop through the recuperator can be written in terms of the geometric variables as

$$
\Delta P=\left(0.79 \ln \frac{4 \dot{m}_{c}(a / b)_{r e g}}{\mu D_{h, r e g}\left(a / b_{r e g}+1\right)^{2}}-1.64\right)^{-2}\left(\frac{8 \dot{m}_{c}^{2}(a / b)_{r e g}^{2}}{\rho\left(a / b_{r e g}+1\right)^{4}}\right)\left(L_{r e g} / D_{h, r e g}{ }^{5}\right)
$$

For the recuperator, the following assumptions were made: the thickness of the material between the hot and cold stream, $t$, is constant at $1 \mathrm{~mm}$ and copper is used as material with thermal conductivity of $k_{\text {solid }}=401 \mathrm{~W} / \mathrm{mK}$. The recuperator efficiency is calculated using the $\varepsilon-N T U$ method with the fouling factor for air given as $F=0.004$ [35]. 


\subsection{Compressor and turbine properties}

Forty-five standard micro-turbines have been considered in previous work [31], however, in this analysis, a single micro-turbine is considered extensively, $M T=41$. The compressor pressure ratio $\left(r=P_{2} / P_{1}\right)$ can be chosen to be a parameter when considering geometric optimisation [36]. The compressor efficiency, mass flow rate and compressor pressure ratio are intrinsically coupled to each other, when considering standard micro-turbines from Honeywell [37].

The highest compressor efficiency is on the island in the middle of a compressor map (between two mass flow rate values: $\dot{m}_{\text {low }}$ and $\dot{m}_{\text {high }}$, and between two pressure ratio values: $r_{\text {low }}$ and $\left.r_{\text {high }}\right)$. Different operating points on the island of maximum compressor efficiency of a micro-turbine can be considered with the straight-line approximation of

$$
\dot{m}=\frac{\left(\dot{m}_{\text {high }}-\dot{m}_{\text {low }}\right)}{\left(r_{\text {high }}-r_{\text {low }}\right)}\left(r-r_{\text {low }}\right)+\dot{m}_{\text {low }}
$$

\subsection{The objective function}

\subsubsection{Temperatures and pressures in terms of geometry variables}

The objective function requires the values of the temperatures and pressures at each point in Fig. 1. An iteration is required. Firstly, $T_{1}=300 \mathrm{~K}$ and $P_{1}=P_{10}=P_{11}=80 \mathrm{kPa}$ (see Fig. 1). The temperatures and pressures in all the ducts are calculated with an assumed temperature loss or pressure drop, which is small. The iteration starts with $T_{5}=800 \mathrm{~K} . P_{4}$ and $P_{9}$ are calculated using Eq. (14). Eq. (16) and Eq. (17) and the recuperator efficiency are employed to calculate the remaining unknowns to produce a new approximation for $T_{5}$. The iteration continues until the error is smaller than $1 \times 10^{-3}$.

$$
T_{6}=\left(\sum_{i=0}^{10} y_{i}{\sqrt{D_{h, r e c} L_{r e c} / 2 \pi}}^{i}\right) / \dot{m} c_{p 0}+T_{5}
$$




$$
P_{6}=P_{5}-\left(0.79 \ln \frac{4 \dot{m}}{\mu \pi D_{h, r e c}}-1.64\right)^{-2}\left(\frac{8 \dot{m}^{2}}{\rho \pi^{2}}\right)\left(\frac{L_{r e c}}{D_{h, r e c} 5}\right)
$$

\subsubsection{Construction of the objective function}

When doing an exergy analysis for the system and assuming $V_{l}=V_{11}$ and $Z_{1}=Z_{11}$, the objective function can be assembled as given in Eq. (18). The function to be maximised (the objective function), is $\dot{W}_{n e t}$ (the net power output). Eq. (19) shows the total entropy generation rate in terms of the temperatures and pressures (with reference to Fig. 1). The entropy generation rate for each component is added and is shown in block brackets. Also note that $\dot{Q}^{*}-\dot{Q}_{\text {loss }}=\dot{Q}_{\text {net }}$.

$\dot{W}_{n e t}=-T_{0} \dot{S}_{g e n, \text { int }}+\left(1-\frac{T_{0}}{T *}\right) \dot{Q}^{*}+\dot{m} c_{p 0}\left(T_{1}-T_{11}\right)-\dot{m} T_{0} c_{p 0} \ln \left(T_{1} / T_{11}\right)$

where

$$
\begin{aligned}
& \dot{S}_{g e n, \text { int }}=\left[-\dot{m} c_{p 0} \ln \left(T_{1} / T_{2}\right)+\dot{m} R \ln \left(P_{1} / P_{2}\right)\right]_{\text {compressor }} \\
& +\left[\dot{Q}_{l} / T_{0}+\dot{m} c_{p 0} \ln \left(T_{3} / T_{2}\right)-\dot{m} R \ln \left(P_{3} / P_{2}\right)\right]_{\text {Duct } 23} \\
& +\left[\dot{m} c_{p 0} \ln \left[\frac{T_{10} T_{4}}{T_{9} T_{3}}\left(\frac{P_{10} P_{4}}{P_{9} P_{3}}\right)^{-R / c_{p 0}}\right]+\dot{Q}_{l} / T_{0}\right]_{\text {recuperato } r} \\
& +\left[\dot{Q}_{l} / T_{0}+\dot{m} c_{p 0} \ln \left(T_{5} / T_{4}\right)-\dot{m} R \ln \left(P_{5} / P_{4}\right)\right]_{\text {Duct } 45} \\
& +\left[-\dot{Q}^{*} / T *+\dot{Q}_{\text {loss }} / T_{0}+\dot{m} c_{p 0} \ln \left(T_{6} / T_{5}\right)-\dot{m} R \ln \left(P_{6} / P_{5}\right)\right]_{\text {receiver }} \\
& +\left[\dot{Q}_{l} / T_{0}+\dot{m} c_{p 0} \ln \left(T_{7} / T_{6}\right)-\dot{m} R \ln \left(P_{7} / P_{6}\right)\right]_{\text {Duct } 67} \\
& +\left[-\dot{m} c_{p 0} \ln \left(T_{7} / T_{8}\right)+\dot{m} R \ln \left(P_{7} / P_{8}\right)\right]_{\text {turbine }}
\end{aligned}
$$


$+\left[\dot{Q}_{l} / T_{0}+\dot{m} c_{p 0} \ln \left(T_{9} / T_{8}\right)-\dot{m} R \ln \left(P_{9} / P_{8}\right)\right]_{\text {Duct89 }}$

\subsubsection{Constraints}

The concentration ratio between concentrator area and receiver aperture area, $C R$, is constrained to $C R_{\min }$.

$D_{h, \text { rec }} L_{\text {rec }} / 8-A_{s, \text { conc }} / C R_{\min } \leq 0$

Eq. (21) prevents the receiver from losing its cavity shape, by only allowing a minimum of two diameters in the distance between the aperture edge and the edge of the receiver.

$2 D_{h, r e c}-((\sqrt{3}-1) / 2) \sqrt{D_{h, \text { rec }} L_{r e c} / 2 \pi} \leq 0$

The maximum surface temperature of the copper receiver tube should stay well below its melting temperature. A highest maximum receiver surface temperature of $1200 \mathrm{~K}$ is identified for the analysis $[30,37]$. The surface area of a tube and the Dittus-Boelter equation [38] help to construct Eq. (22), which is the maximum surface temperature of the receiver.

$T_{s, \max }=T_{6}+\dot{Q}_{n e t} /\left(0.023 \pi L_{r e c} k \operatorname{Pr}^{0.4}\left(4 \dot{m} /\left(\mu \pi D_{h, \text { rec }}\right)\right)^{0.8}\right)$

To ensure that the system stays compact and realistic, the recuperator's length should not exceed the length of the radius of the dish,

$L_{\text {reg }} \leq D_{\text {conc }} / 2$ 


\section{Research methodology}

The dynamic trajectory optimisation method for constrained optimisation [39] is used. There are five geometric variables to be optimised: the cavity receiver tube diameter, $D_{\text {rec }}$; the tube length of the cavity receiver, $L_{r e c}$; the hydraulic diameter of the recuperator channels, $D_{h, r e g}$; the length of the recuperator channels, $L_{r e g}$; and aspect ratio of the recuperator channels, $a / b_{\text {reg }}$. The objective function (net power output of the system) in terms of the scaled geometry variables, parameters and constants is maximised using the dynamic trajectory optimisation method by Snyman [39] in MATLAB, with unit step size and convergence tolerance of $1 \times 10^{-7}$. Optimisation of the geometry variables was done at different micro-turbine operating points (along the line of highest compressor efficiency on the compressor map of a specific microturbine).

Each data point represents an optimised system - a system with maximum net power output and optimised receiver and recuperator geometries. In Table 1, the default values are given, for which these results were generated. Note that when the receiver inclination is $90^{\circ}$, the receiver aperture lies in the horizontal plane. The effect on the optimum system, when each of these conditions or parameters is changed individually, is investigated for a system using $M T=41$, and $D_{\text {conc }}=16 \mathrm{~m}$. The behaviour of a system with $M T=41$ was considered because the micro-turbine has a very large operating range in which the compressor efficiency is a maximum. Similar behaviour as found in the results for this specific system configuration could be expected for other configurations of micro-turbines and concentrator diameters [31]. Note that when an individual condition or parameter is changed, the other conditions and parameters stay constant as in the default. Also note that Fig. 3 would change when the wind, inclination, rim angle, surrounding temperature and solar irradiance constants are changed from their default values for which Fig. 3 was generated. 
Table 1. Values used for default analysis and for inspection.

\begin{tabular}{|l|l|l|l|}
\hline $\begin{array}{l}\text { Environmental condition or } \\
\text { parameter }\end{array}$ & Symbol & Default & $\begin{array}{l}\text { Changed values for } \\
\boldsymbol{D}_{\text {conc }}=\mathbf{1 6} \mathbf{~ m , ~ M T}=\mathbf{4 1}\end{array}$ \\
\hline Surrounding temperature & $T_{0}$ & $300 \mathrm{~K}$ & $315 \mathrm{~K}$ \\
\hline Atmospheric pressure & $P_{1}$ & $80 \mathrm{kPa}$ & $100 \mathrm{kPa}$ \\
\hline Solar irradiance & $I$ & $1000 \mathrm{~W} / \mathrm{m}^{2}$ & $1200 \mathrm{~W} / \mathrm{m}^{2}$ \\
\hline Wind factor & $w$ & 1 & 10 \\
\hline Concentrator rim angle & $\varphi_{\text {rim }}$ & $45^{\circ}$ & $30^{\circ}$ \\
\hline Receiver inclination & $\beta$ & $90^{\circ}$ & $45^{\circ}$ \\
\hline Recuperator height & $H$ & $1 \mathrm{~m}$ & $0.5 \mathrm{~m}$ \\
\hline Minimum concentration ratio & $C R_{\min }$ & 100 & 500 \\
\hline
\end{tabular}

\section{Results and discussion}

Fig. 5 shows the maximum net power output, minimum internal and external irreversibility rates and maximum net absorbed heat rate for different operating conditions of Micro-turbine 41 with a concentrator diameter of $16 \mathrm{~m}$, using the default settings in Table 1 . The maximum net power output of the system at each operating condition (mass flow rate), was found by optimising the geometry variables to maximise the objective function. The highest maximum net power output is at the point where the minimum irreversibility rate $\left(\dot{I}_{e x t \text {, min }}+\dot{I}_{\text {int, min }}\right)$ is the lowest. This result is in agreement with the second law of thermodynamics. Fig. 6 shows the maximum net power output for the system. For the default settings, the highest maximum net power output is at a mass flow rate close to $0.6 \mathrm{~kg} / \mathrm{s}$. When the solar irradiance, $I$, is changed from $1000 \mathrm{~W} / \mathrm{m}^{2}$ (the default) to $1200 \mathrm{~W} / \mathrm{m}^{2}$, the highest maximum net power output shifts to a mass flow rate close to $0.67 \mathrm{~kg} / \mathrm{s}$. Take note that the other conditions and parameters stay constant on their default values when a single condition or parameter is investigated. When $C R_{\min }$ is increased from 100 to 500 or when $w$ increases from 1 to 10 , the highest maximum net power output is lower than for the default settings. 
The optimum receiver tube diameter, $D_{\text {rec,opt }}$, is shown in Fig. 7. In most of the cases, when a condition or parameter is changed, $D_{\text {rec, opt }}$ does not differ much from $D_{\text {rec,opt }}$ of the default settings. However, at high mass flow rates, when the wind factor is increased from 1 to 10 and $\varphi_{\text {rim }}$ is changed from $45^{\circ}$ to $30^{\circ}, D_{\text {rec,opt }}$ is smaller. When $C R_{\min }$ is changed from 100 to 500 , $D_{\text {rec,opt }}$ is smaller at any mass flow rate. The optimum receiver channel length, $L_{r e c, o p t}$, is shown in Fig. 8. The only extensive change from $L_{r e c, \text { opt }}$ of the default settings is due to altered $w$, $\varphi_{\text {rim }}$ and $C R_{\min }$, where a shorter tube is required at certain or all mass flow rates.

In Fig. 9, the optimum aspect ratio of the recuperator channels increases as the mass flow rate increases. Note that a much higher optimum aspect ratio is required when the recuperator height is halved from $1 \mathrm{~m}$ to $0.5 \mathrm{~m}$, especially at higher mass flow rates. For the other parameter and condition changes, the optimum recuperator channel aspect ratio does not change much from the optimum of the default. In Fig. 10, the optimum hydraulic diameter of the recuperator channels is shown. For the default, the maximum $D_{h, \text { reg,opt }}$ is close to $0.45 \mathrm{~kg} / \mathrm{s}$ and the minimum is close to $0.625 \mathrm{~kg} / \mathrm{s}$. This minimum is shifted to a higher value when $I, w$ and $C R_{\min }$ are increased individually from its default value to the changed value listed in Table 1. The maximum $D_{h, r e g, o p t}$ is shifted to a different mass flow rate when $H, w, I$ and $C R_{\text {min }}$ are changed. Fig. 11 shows that the optimum recuperator length converges to its constraint. For the default settings, the constraint of $8 \mathrm{~m}$ is reached at a mass flow rate of about 0.425 $\mathrm{kg} / \mathrm{s}$. This mass flow rate is higher when $I$ and $C R_{\min }$ are changed, while when $w$ is changed, it is lower.

A lowest and a highest optimum recuperator mass flow rate exist as shown in Fig. 12. Note how this minimum and maximum are shifted due to the changed parameters and conditions of $H, I, w$ and $C R_{\min }$. A very high $\dot{m}_{\text {reg,opt }}$ is noted at a system mass flow rate close to $0.425 \mathrm{~kg} / \mathrm{s}$ when $H$ is halved from $1 \mathrm{~m}$ to $0.5 \mathrm{~m}$. In Fig. 13, the optimum recuperator $N T U$ is shown. For the default settings, a maximum is observed close to $0.625 \mathrm{~kg} / \mathrm{s}$. This maximum is shifted to a higher mass flow rate when $I, w$ and $C R_{\min }$ are changed. When the atmospheric pressure is changed from $80 \mathrm{kPa}$ to $100 \mathrm{kPa}$, a higher optimum $N T U$ is reached.

The minimum external and internal irreversibility rates are shown in Figs. 14 and 15. The lowest irreversibility rates exist at a mass flow rate close to $0.6 \mathrm{~kg} / \mathrm{s}$. This minimum is only shifted to a different mass flow rate, when $I, w$, and $C R_{\min }$ are changed. The maximum net 
absorbed heat rate is shown in Fig. 16. Note the sacrifice of $\dot{Q}_{n e t, \max }$ due to wind at small mass flow rates and the higher $\dot{Q}_{n e t, \max }$ when $I$ is changed from $1000 \mathrm{~W} / \mathrm{m}^{2}$ to $1200 \mathrm{~W} / \mathrm{m}^{2}$.

The minimum internal entropy generation rates due to temperature difference and pressure drop in the recuperator are shown in Figs. 17 and 18. For the default values, $\dot{S}_{g e n, \text { int,min, } \Delta T}$ reaches a maximum at a mass flow rate of $0.38 \mathrm{~kg} / \mathrm{s}$. As the mass flow rate increases further, $\dot{S}_{g e n, \text { int, min, } \Delta T}$ decreases. This behaviour was only altered when $I, w$ and $C R_{\min }$ were changed. The change in $I$ shifts the maximum $\dot{S}_{g e n, \text { int,min, } \Delta P}$ (Fig. 18) quite significantly. The minimum internal entropy generation rates due to temperature difference and pressure drop in the receiver are shown in Figs. 19 and 20. Only the changes in $I, w$ and $C R_{\min }$ deflect the minimum entropy generation rates from those obtained with the default settings. Also note that $\dot{S}_{\text {gen,int,min, } \Delta P}$ (Fig. 20) is increased at high mass flow rates, when $\varphi_{\text {rim }}$ is changed from $45^{\circ}$ to $30^{\circ}$. In Fig. 21, the maximum receiver surface temperature of the optimised system stays constant at $1200 \mathrm{~K}$ up to a certain mass flow rate, whereafter it decreases. This is due to the maximum surface temperature constraint of $1200 \mathrm{~K}$. This specific mass flow rate is only significantly changed by changing $I$ or $C R_{\min }$.

From the results, a few concluding comments can be made. A changed rim angle, halved recuperator height and receiver inclination did not change the maximum net power output (Fig. 6), but it did, however, change the optimum geometries of the receiver and recuperator (Figs. 7 -11). At larger mass flow rates, it is more beneficial for the system to have a smaller receiver (Figs. 7 and 8) during heavy wind, high concentration ratios and lower rim angles. At small mass flow rates, the optimum hydraulic diameter and length of the recuperator (Fig. 10 11) increase as the system mass flow rate increases, until the recuperator length constraint is reached. It is shown that a unique set of optimum geometry variables exist for each state of the surrounding conditions. These results can be important in the preliminary stages of design.

A close similarity is identified between the minima and maxima of Figs. 10 and 12. From Fig. 13, it is most beneficial for a system with a small mass flow rate to have a small NTU. Note that the highest maximum net power output for the default settings in Fig. 6 is not necessarily a maximum when the $N T U$ is at its highest.

$\dot{I}_{e x t}=\dot{m} c_{p 0}\left(T_{1}-T_{11}\right)-\dot{m} T_{0} c_{p 0} \ln \left(T_{1} / T_{11}\right)$ 
$\dot{I}_{\text {ext,min }}$ seems to be at a maximum when the mass flow rate is small (Figs. 5 and 14). From Eq. (24), it follows that, for high external irreversibilities, $T_{11}$ must be high, which means that the recuperator efficiency should be small. This is why the optimum NTU is small at small mass flow rates, as shown in Fig. 13. Note that a small $N T U$ corresponds with a large hydraulic diameter (Fig. 10) and large recuperator channel mass flow rate (Fig. 12).

For the recuperator (Figs. 17 and 18) and receiver (Figs. 19 and 20), $\dot{S}_{g e n, \text { int,min, } \Delta T}$ is almost always larger than $\dot{S}_{g e n, \text { int,min, } \Delta P}$. The total minimum entropy generation rate in the receiver is much larger than the total minimum entropy generation rate in the recuperator. Also note the low minimum entropy generation rate due to fluid friction in the recuperator, $\dot{S}_{g e n, \text { int, min, } \Delta P}$

(Fig. 18) at small mass flow rates. At larger mass flow rates, $\dot{S}_{g e n, \text { int,min, } \Delta P}$ is increased because of the small hydraulic diameter (Fig. 10).

\section{Conclusion}

The small-scale open and direct solar thermal Brayton cycle with recuperator has several advantages, but the main disadvantages of this cycle are the pressure losses in the recuperator and receiver, turbomachine efficiencies and recuperator effectiveness, which limit the net power output of such a system. In this paper, a modified cavity receiver and a counterflow plate-type recuperator were optimally sized so that the system can have maximum net power output at a steady-state condition. A sizing algorithm was used to establish the net absorbed heat rate of the cavity receiver as a function of the receiver aperture diameter for a specific concentrator diameter with fixed focal length and rim angle. An off-the-shelf micro-turbine with a wide maximum compressor efficiency operating range was used in the analysis. The dynamic trajectory optimisation method for constrained optimisation was applied. The net power output of the system was described in terms of the total entropy generation rate within the system for various cases of wind, receiver inclination, concentrator rim angle, atmospheric pressure and temperature, recuperator height, solar irradiance and minimum concentration ratio. Results showed that, for a specific environment and set of parameters, optimum receiver 
and recuperator geometries exist so that the system can produce its inherent maximum net power output. These results should be strengthened by an experimental study.

\section{Acknowledgements}

The authors acknowledge with gratitude the support from the University of Pretoria and the National Research Foundation (NRF-DST).

\section{References}

[1] Chen L, Zhang W., Sun F. Power, efficiency, entropy-generation rate and ecological optimization for a class of generalized irreversible universal heat-engine cycles. Applied Energy 2007; 84:512-25.

[2] Mills D. Advances in solar thermal electricity technology. Solar Energy 2004; 76:19-31.

[3] Stine BS, Harrigan RW. Solar energy fundamentals and design. New York: John Wiley; 1985.

[4] Bejan A. Entropy generation through heat and fluid flow. Colorado: John Wiley; 1982.

[5] Bejan A. Method of entropy generation minimization, or modeling and optimization based on combined heat transfer and thermodynamics. Rev Gén Therm 1996; 35:637-46.

[6] Bejan A. Advanced engineering thermodynamics. $2^{\text {nd }}$ ed. Durham: John Wiley; 1997.

[7] Bejan A, Tsatsaronis G, Moran M. Thermal design and optimization. New York: John Wiley; 1996.

[8] Ordóñez JC, Bejan A. Entropy generation minimization in parallel-plates counterflow heat exchangers. International Journal of Energy Research 2000; 24:843-64.

[9] Shiba T, Bejan A. Thermodynamic optimization of geometric structure in the counterflow heat exchanger for an environmental control system. Energy 2001; 26:493-511.

[10] Zimparov VD, Da Silva AK, Bejan A. Thermodynamic optimization of tree-shaped flow geometries with constant channel wall temperature. International Journal of Heat and Mass Transfer 2006; 49:4839-49.

[11] Zimparov VD, Da Silva AK, Bejan A. Thermodynamic optimization of tree-shaped flow geometries. International Journal of Heat and Mass Transfer 2006; 49:1619-30.

[12] Ratts BE, Raut AG. Entropy generation minimization of fully developed internal flow with constant heat flux. Journal of Heat Transfer 2004; 126(4):656-9. 
[13] Sarangi S, Chowdhury K. On the generation of entropy in a counterflow heat exchanger. Cryogenics 1982; 22(2):63-5.

[14] Cornelissen RL, Hirs GG. Exergetic optimization of a heat exchanger. Energy Conversion and Management 1997; 1(15-17):1567-76.

[15] Zimparov V. Extended performance evaluation criteria for enhanced heat transfer surfaces: heat transfer through ducts with constant heat flux. International Journal of Heat and Mass Transfer 2001; 44(1):169-80.

[16] Hesselgreaves JE. Rationalisation of second law analysis of heat exchangers. International Journal of Heat and Mass Transfer 2000; 43(22):4189-204.

[17] Oğulata RT, Doba F, Yilmaz T. Irreversibility analysis of cross flow heat exchangers. Energy Conversion \& Management 2000; 41(15):1585-99.

[18] Shuai Y, Xia X, Tan H. Radiation performance of dish solar concentrator/cavity receiver systems. Solar Energy 2008; 82:13-21.

[19] Prakash M, Kedare SB, Nayak JK. Investigations on heat losses from a solar cavity receiver. Solar Energy 2009; 83:157-70.

[20] Sendhil Kumar N, Reddy KS. Comparison of receivers for solar dish collector system. Energy Conversion and Management 2008; 49:812-9.

[21] Sendhil Kumar N, Reddy KS. Numerical investigation of natural convection heat loss in modified cavity receiver for fuzzy focal solar dish concentrator. Solar Energy 2007; 81:84655.

[22] Reddy KS, Sendhil Kumar N. Combined laminar natural convection and surface radiation heat transfer in a modified cavity receiver of solar parabolic dish. International Journal of Thermal Sciences 2008; 47:1647-57.

[23] Reddy KS, Sendhil Kumar N. An improved model for natural convection heat loss from modified cavity receiver of solar dish concentrator. Solar Energy 2009; 83:1884-92.

[24] Torres Reyes E, Picon Nunez M, Cervantes de G J. Exergetic analysis and optimization of a solar-assisted heat pump. Energy 1998; 23(4):337-344.

[25] Ameri M, Behbahaninia A, Abbas Tanha A. Thermodynamic analysis of a tri-generation system based on micro-gas turbine with a steam ejector refrigeration system. Energy 2010; 35:2203-2209. 
[26] Blanco-Marigorta AM, Victoria Sanchez-Henríquez M, Peña-Quintana JA. Exergetic comparison of two different cooling technologies for the power cycle of a thermal power plant. Energy 2011; 36:1966-1972.

[27] Jubeh NM. Exergy analysis and second law efficiency of a regenerative Brayton cycle with isothermal heat addition. Entropy 2005; 7(3):172-87.

[28] Sarkar J. Thermodynamic analyses and optimization of a recompression $\mathrm{N}_{2} \mathrm{O}$ Brayton power cycle. Energy 2010; 35:3422-3428.

[29] Wu C, Chen L, Sun F. Performance of a regenerative Brayton heat engine. Energy 1996; 21(2):71-76.

[30] Shah RK. Micro gas turbines, 2, Compact heat exchangers for microturbines. Neuilly-surSeine, France: RTO; 2005. Available from: http://www.rto.nato.int/abstracts.asp.

[31] Le Roux WG, Bello-Ochende T, Meyer JP. Thermodynamic optimization of an integrated design of a small-scale solar thermal Brayton cycle. International Journal of Energy Research 2011, doi: 10.1002/er.1859.

[32] Burden RL, Faires JD. Numerical analysis. $8^{\text {th }}$ ed. Youngston State University: Thomson Brooks/Cole; 2005.

[33] Gnielinski V. New equations for heat and mass transfer in turbulent pipe and channel flow. International Chemical Engineering 1976; 16:359-68.

[34] Petukhov BS. Heat transfer and friction in turbulent pipe flow with variable physical properties. Advances in Heat Transfer 1970; 6.

[35] Çengel YA. Heat and mass transfer. $3^{\text {rd }}$ ed. Nevada, Reno: McGraw-Hill; 2006.

[36] Snyman JA. Practical mathematical optimization. Pretoria: University of Pretoria; 2009.

[37] Garrett. Garrett by Honeywell: turbochargers, intercoolers, upgrades, wastegates, blowoff valves, turbo-tutorial; 2009. Available at: http://www.TurboByGarrett.com.

[38] Dittus FW, Boelter LMK. University of California publications on engineering 1930; 2:433.

[39] Snyman JA. The LFOPC leap-frog algorithm for constrained optimization. Computers and Mathematics with Applications 2000; 40:1085-96. 


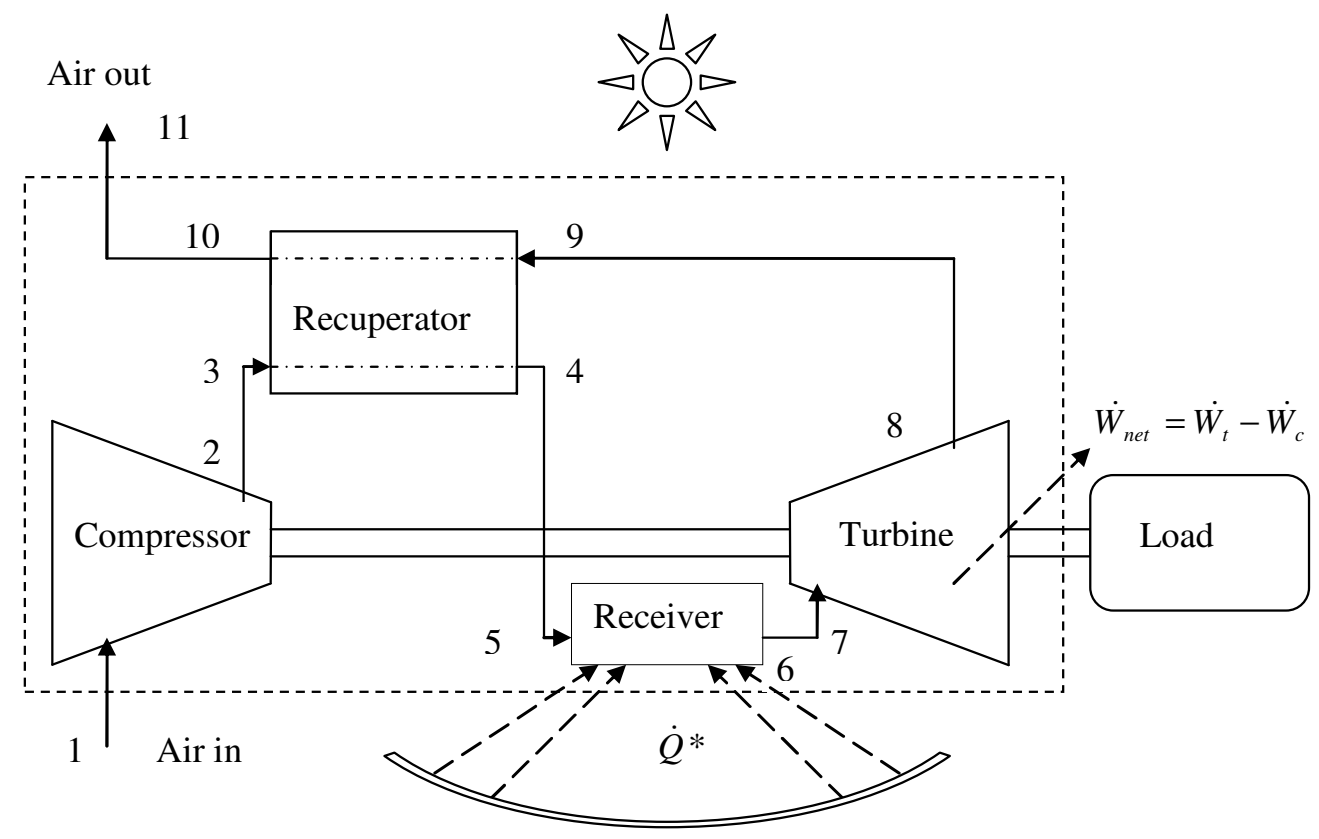

Fig. 1 


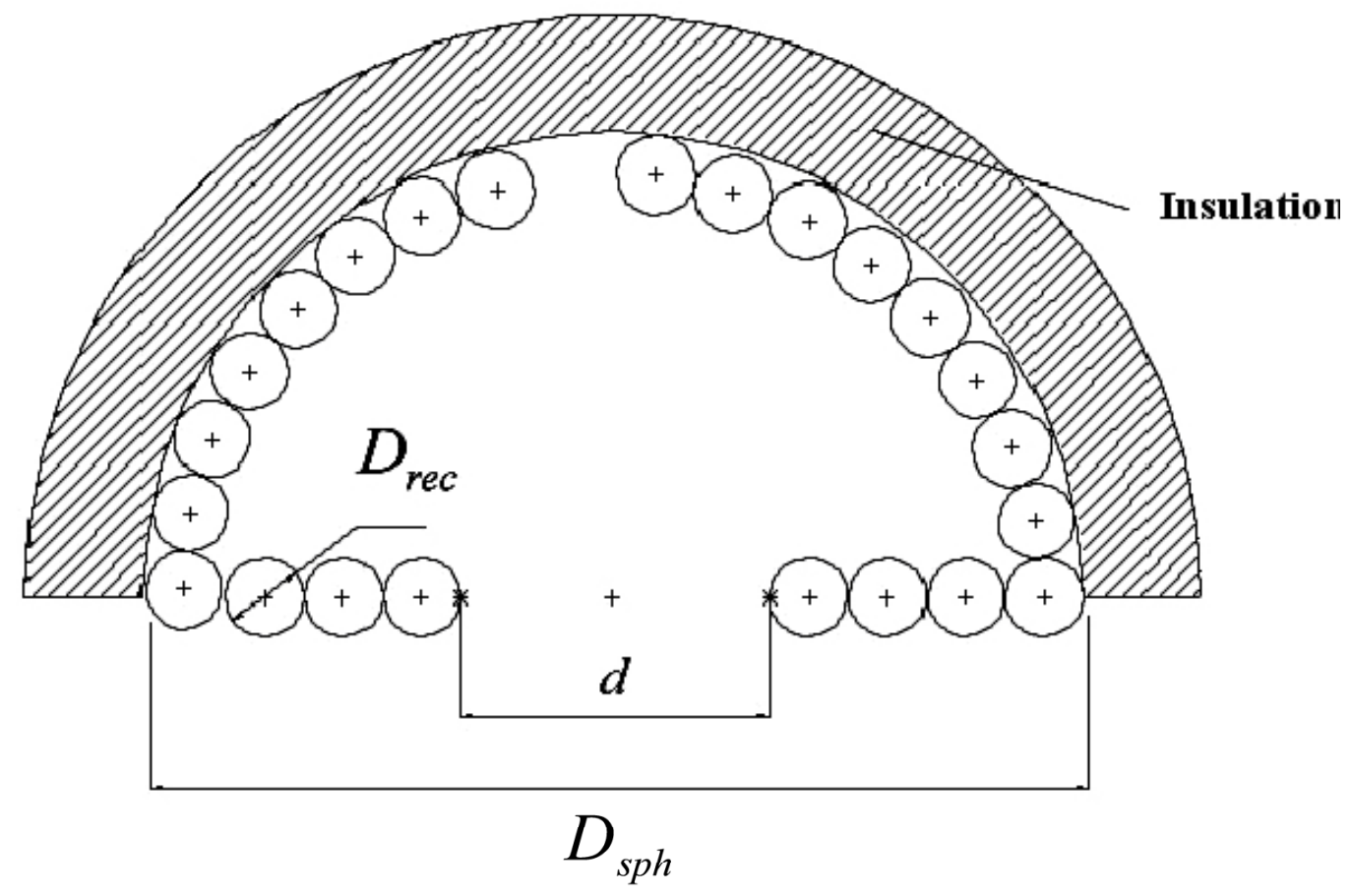

Fig. 2 


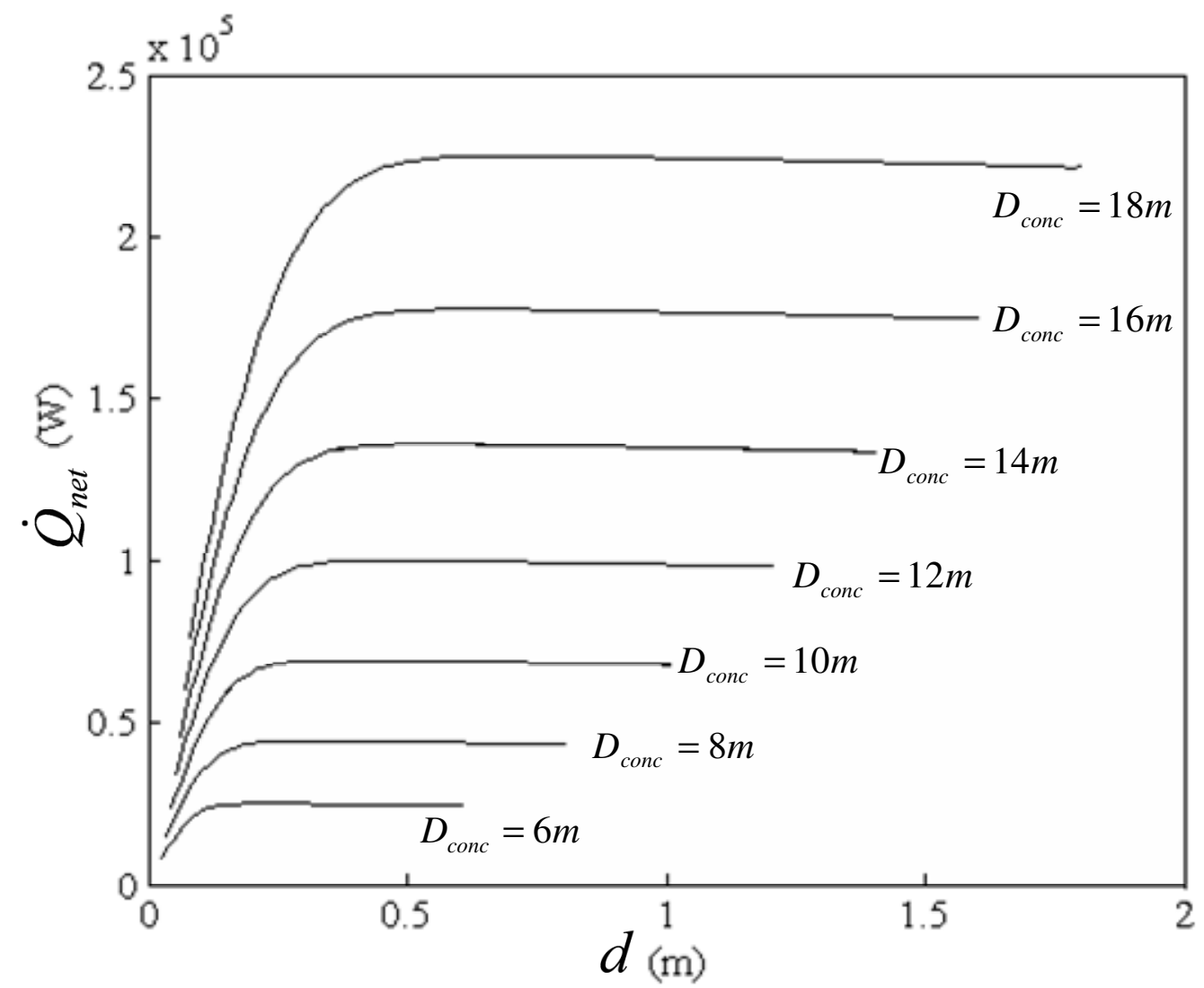

Fig. 3 


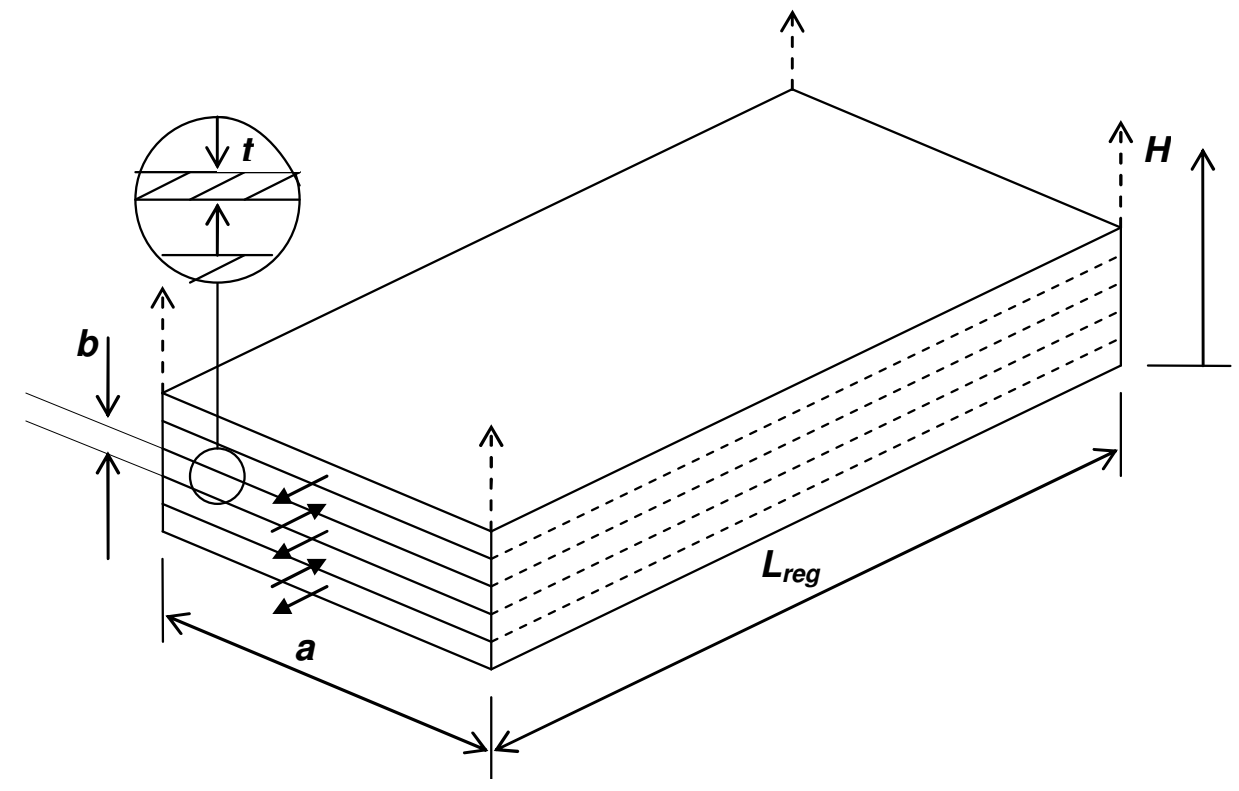

Fig. 4 


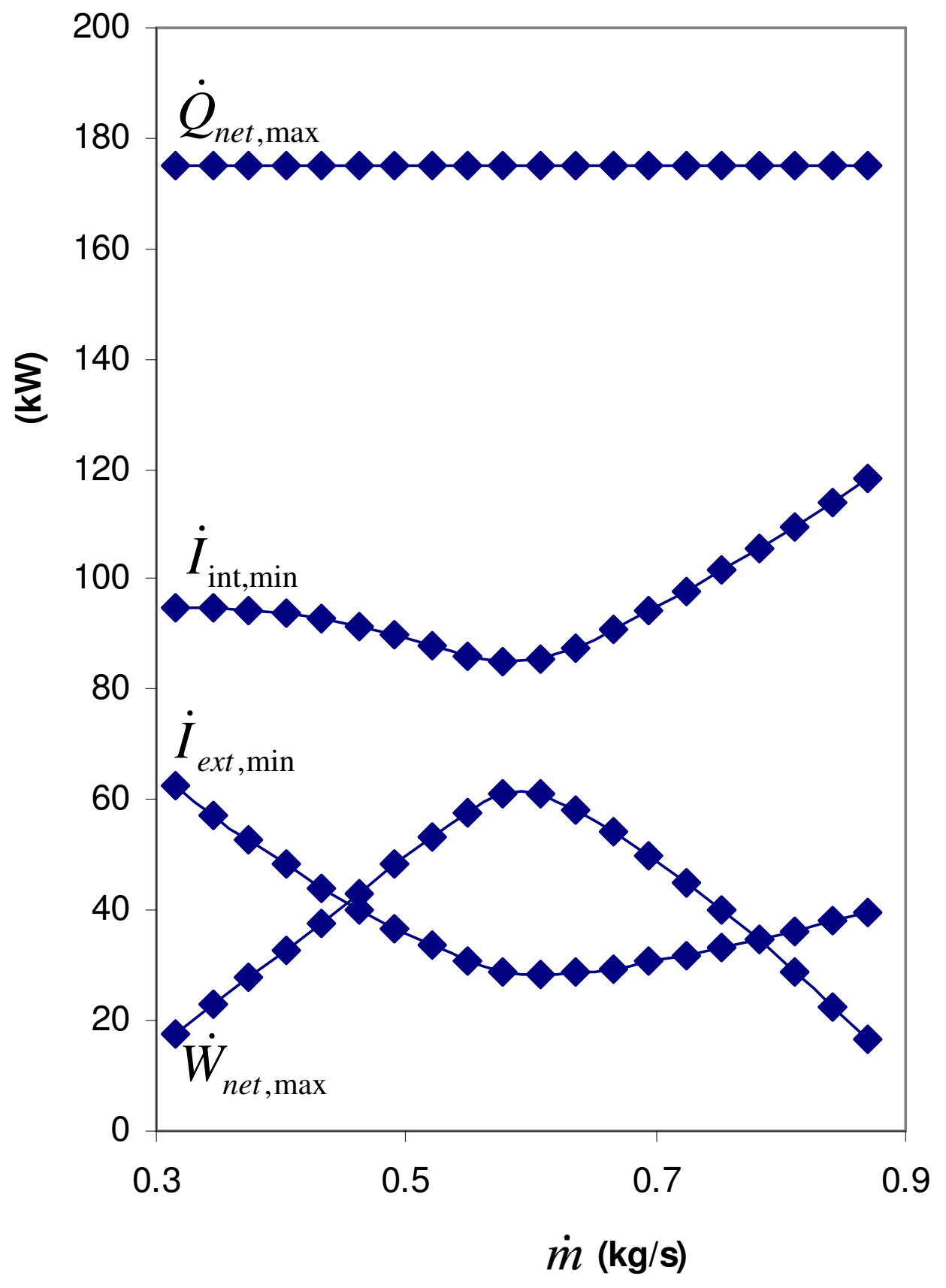

Fig. 5 


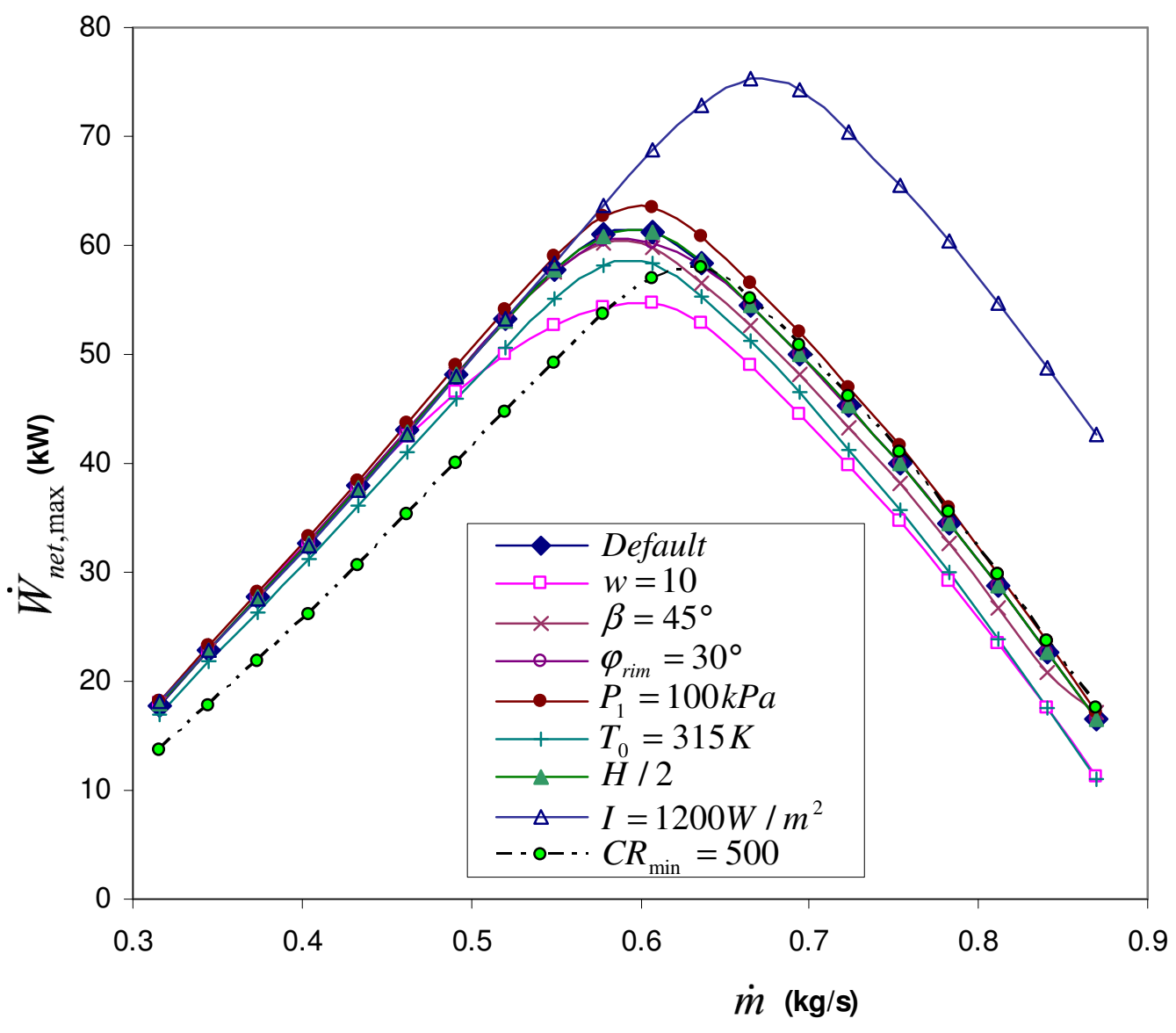

Fig. 6 


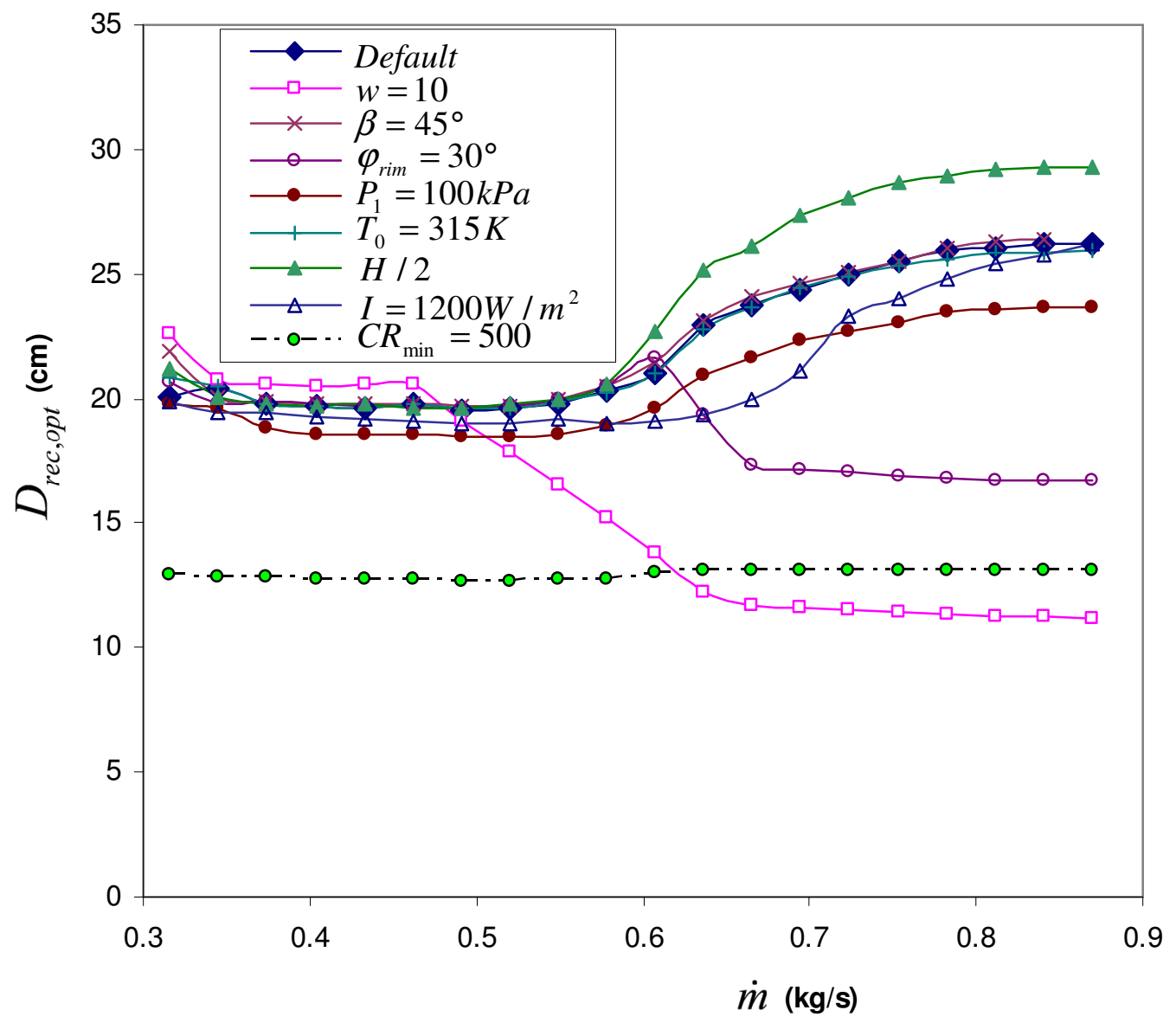

Fig. 7 


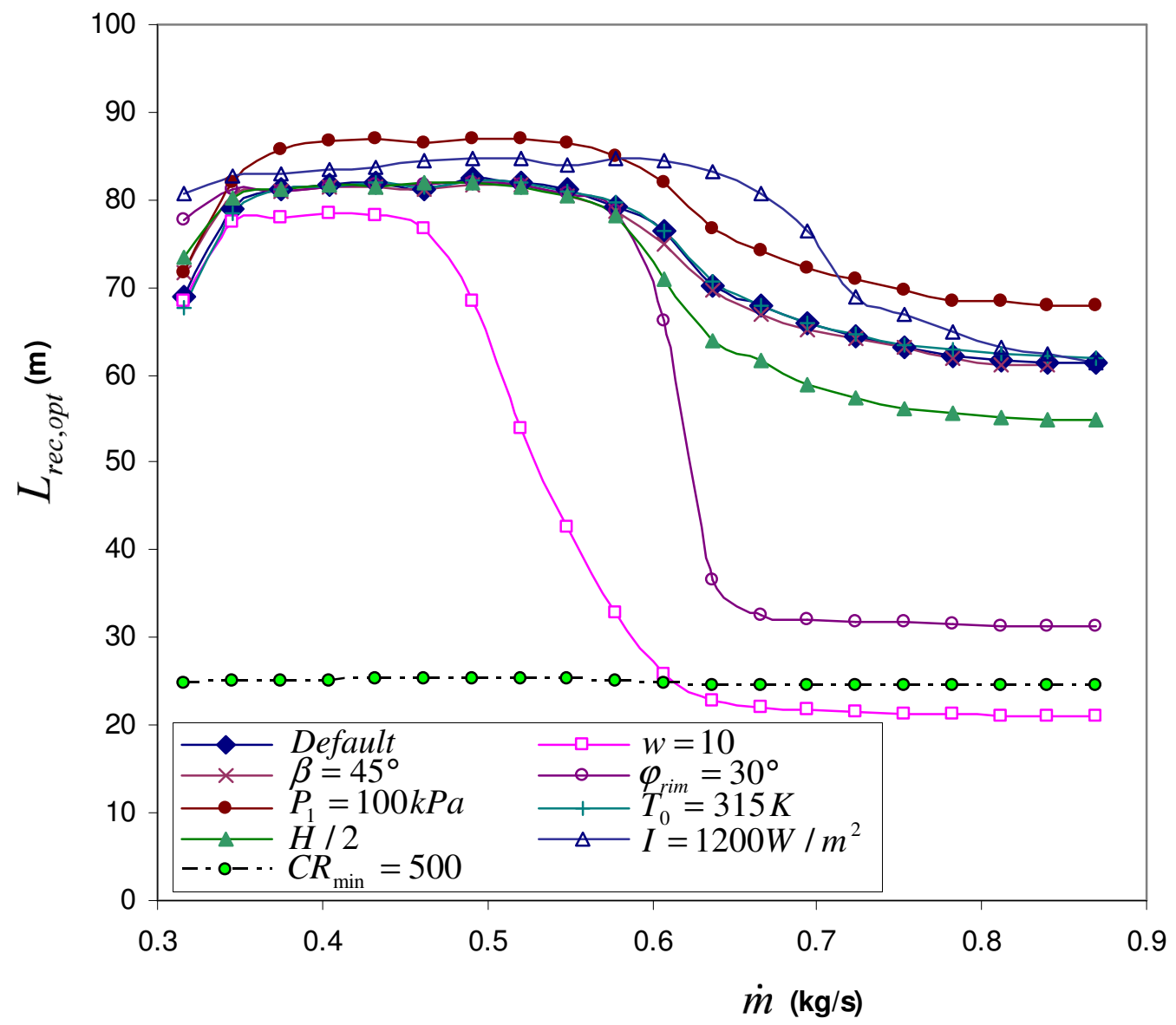

Fig. 8 


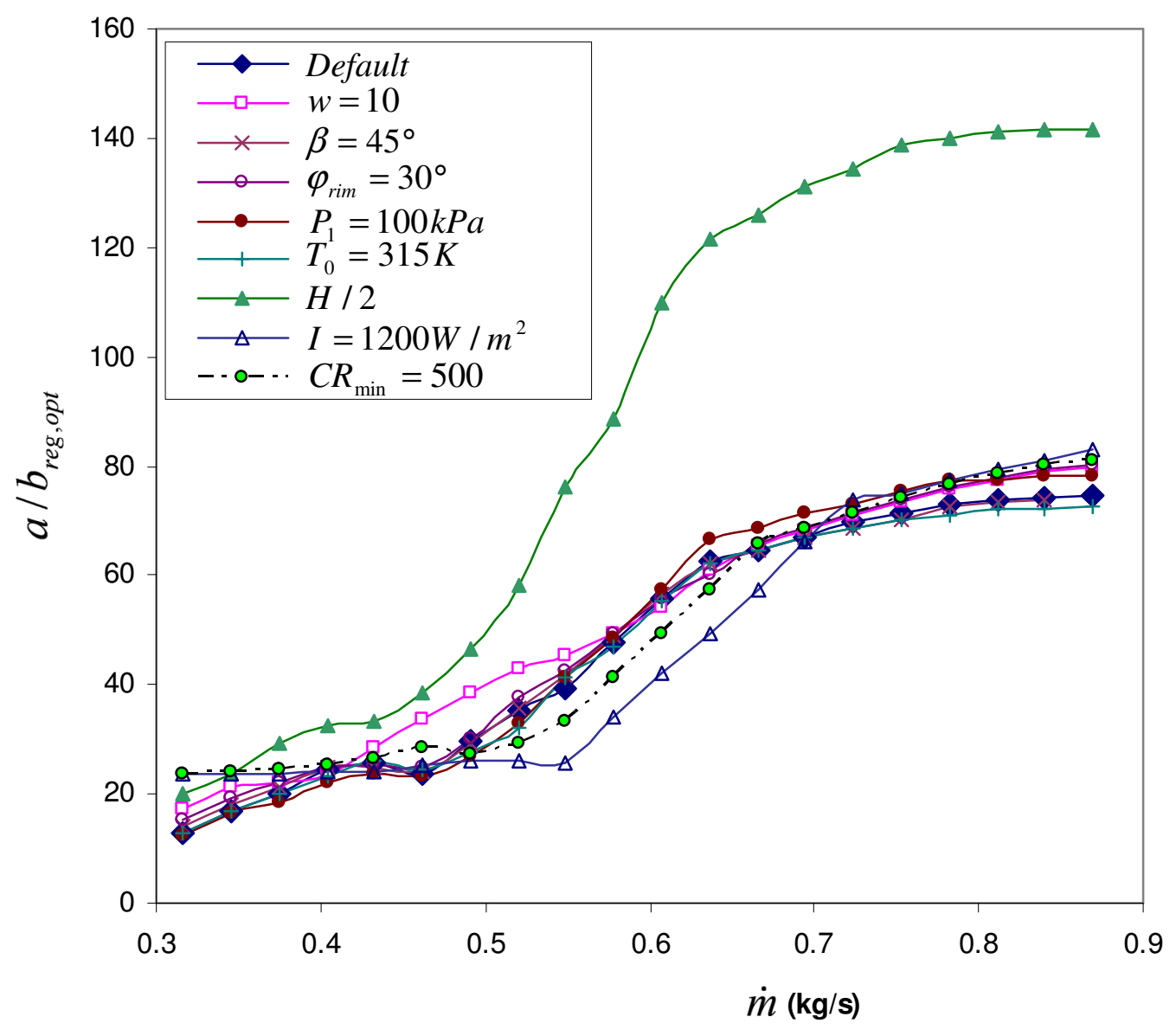

Fig. 9 


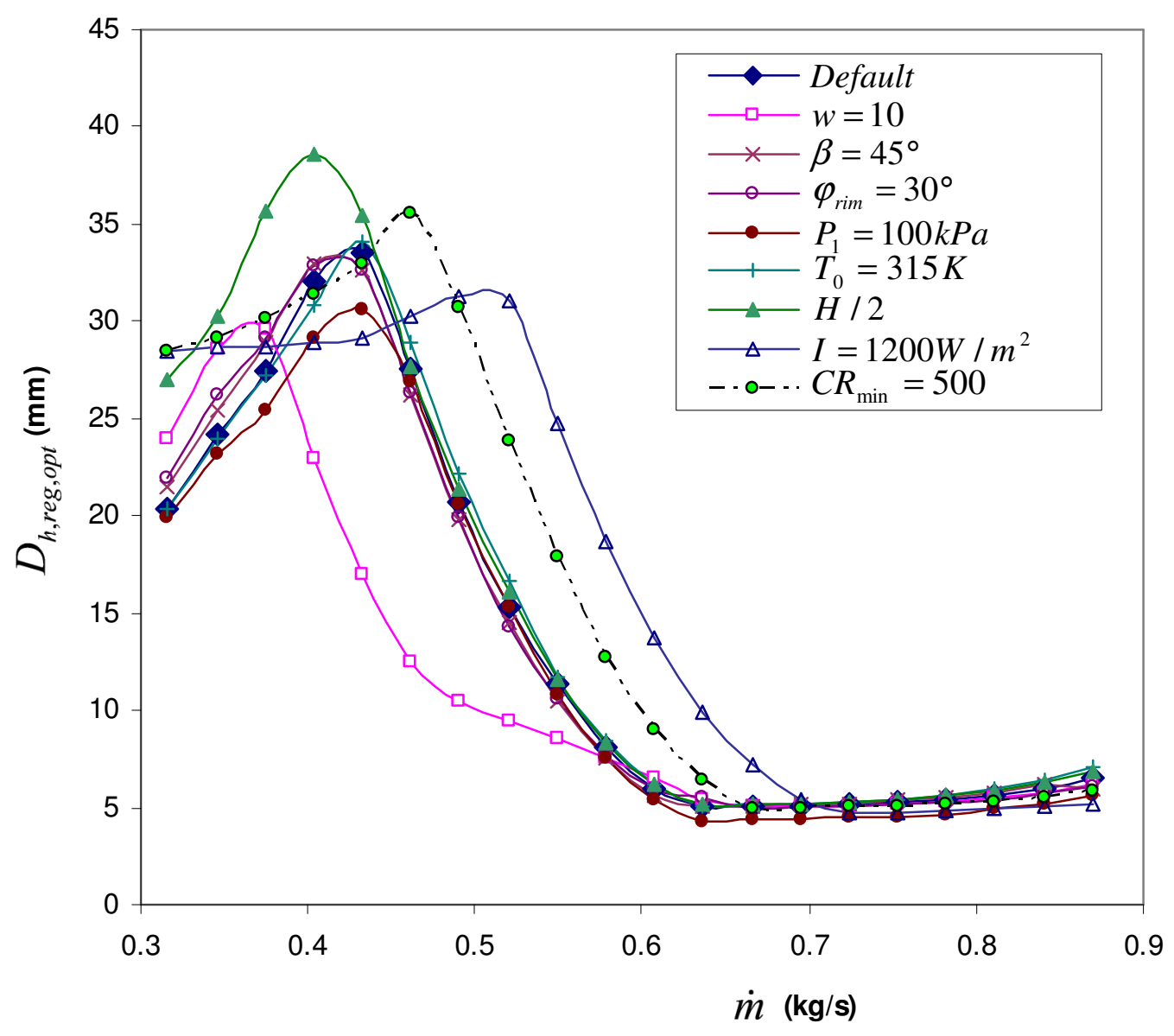

Fig. 10 


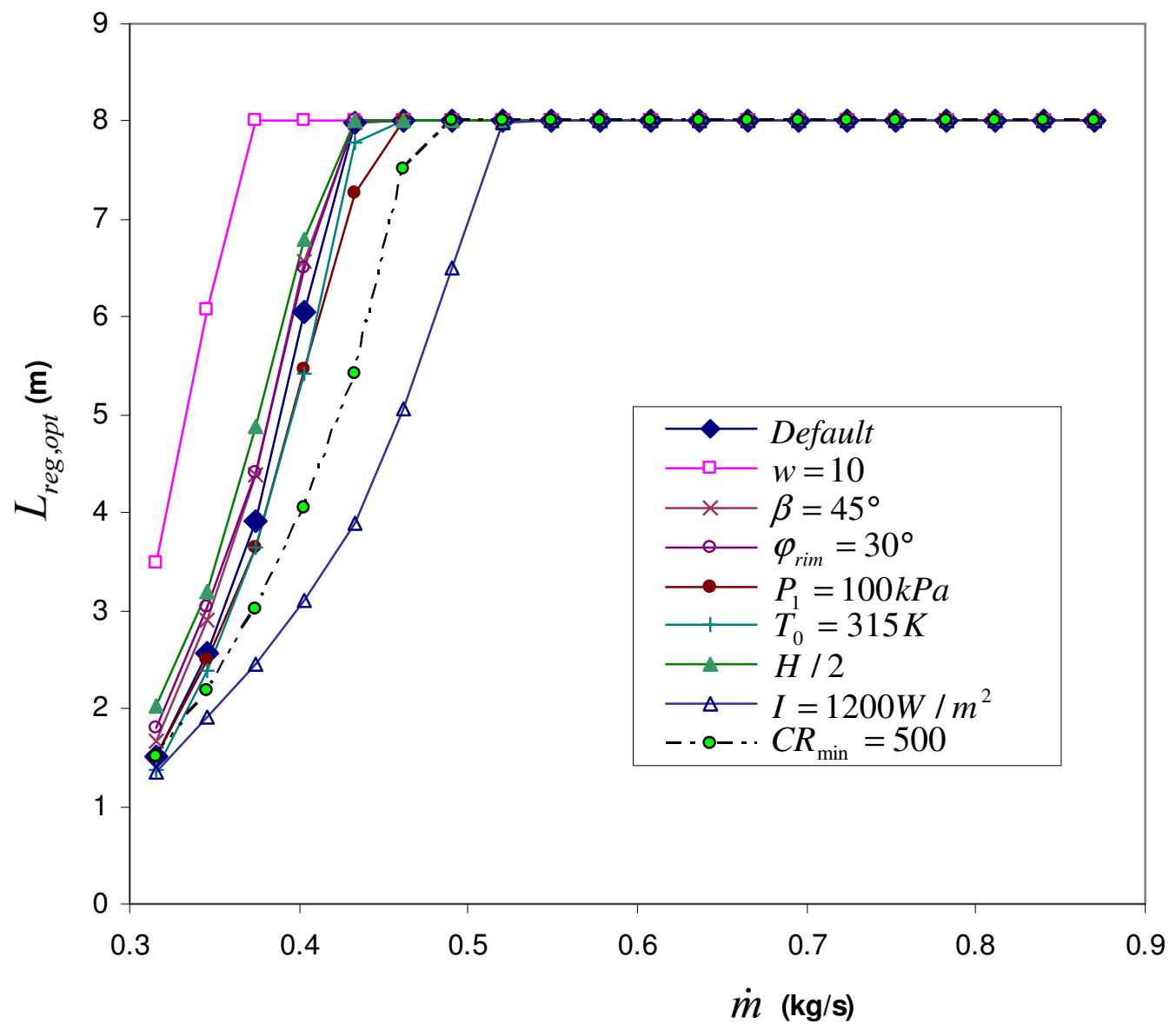

Fig. 11 


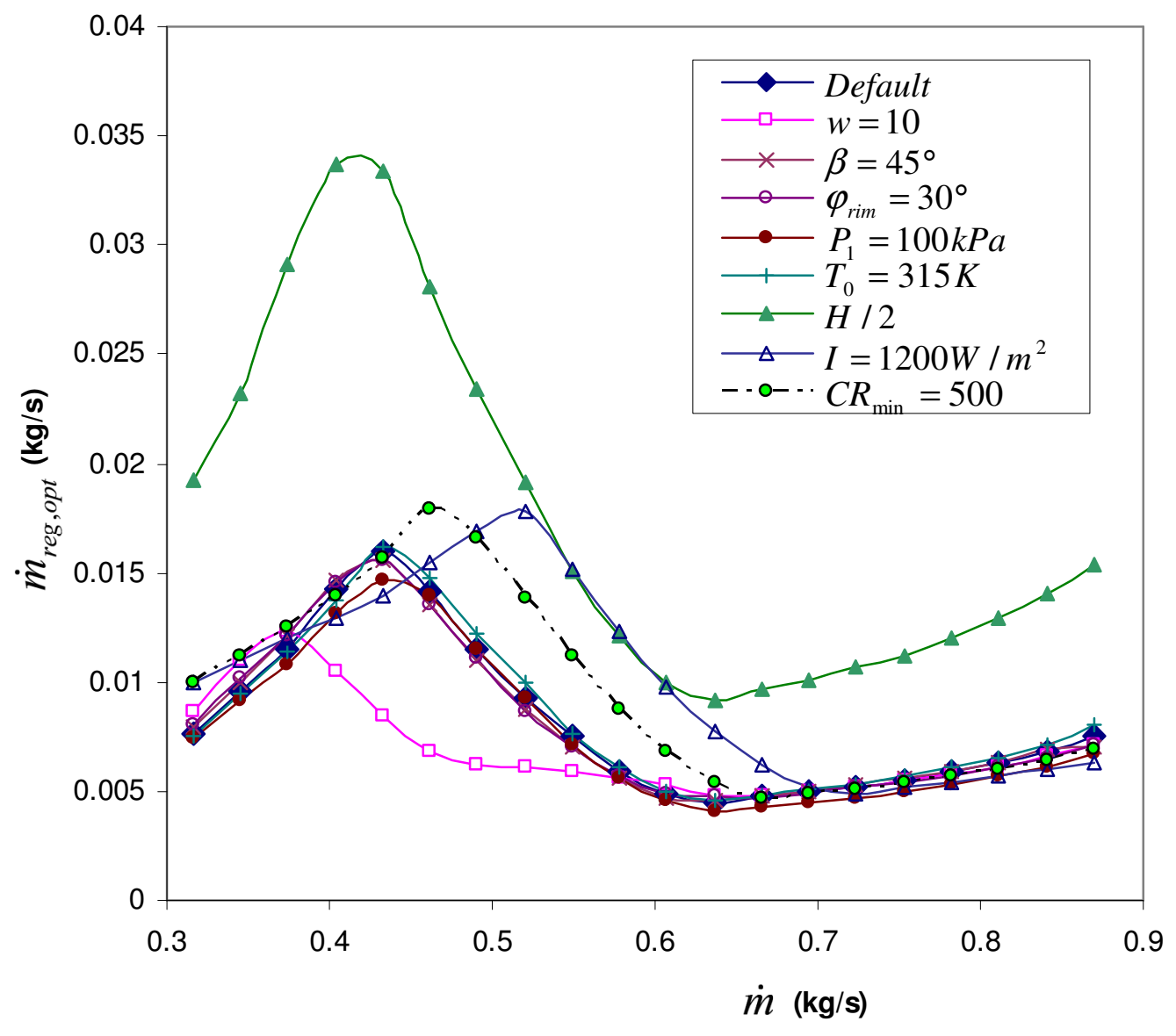

Fig. 12 


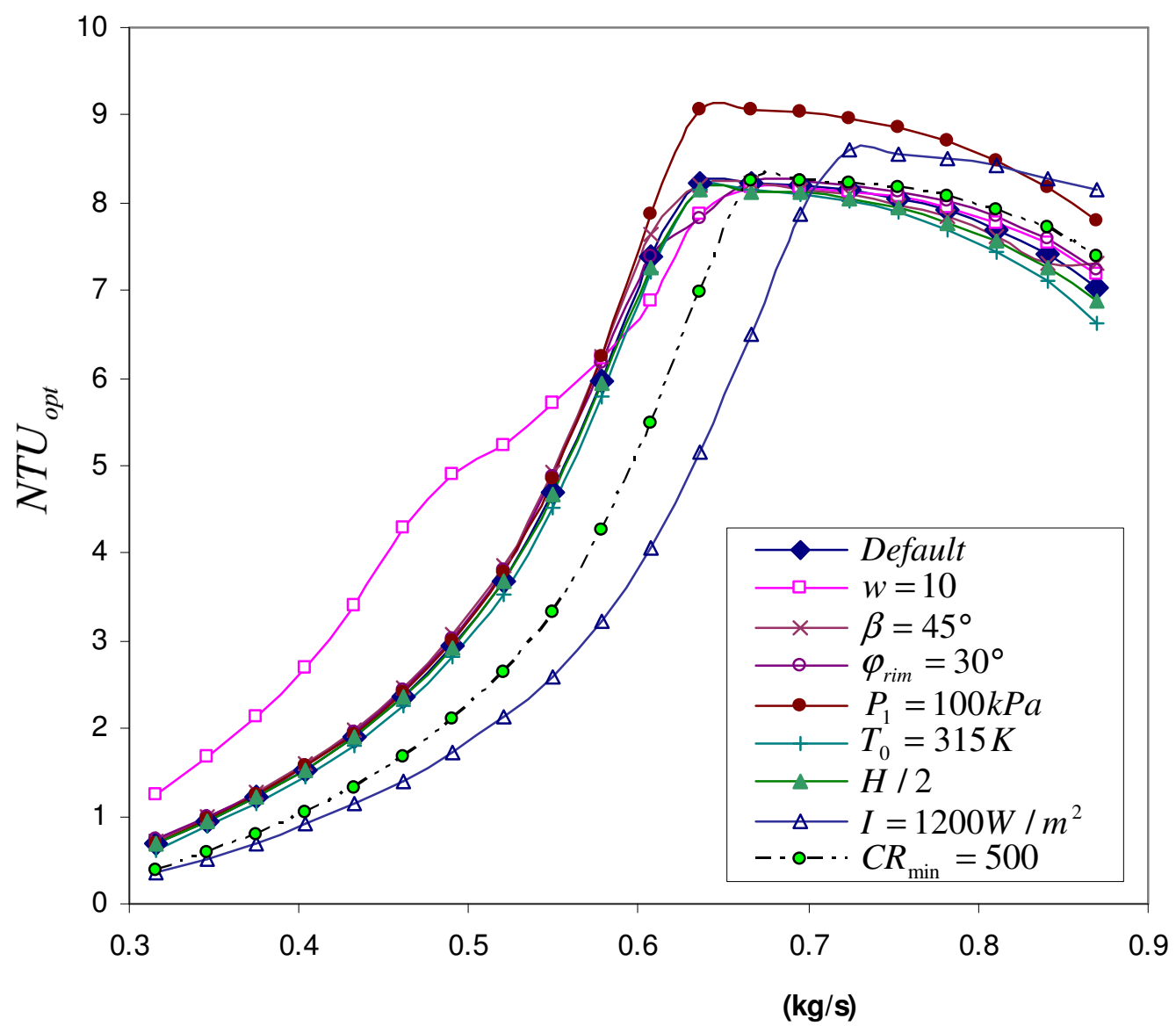

Fig. 13 


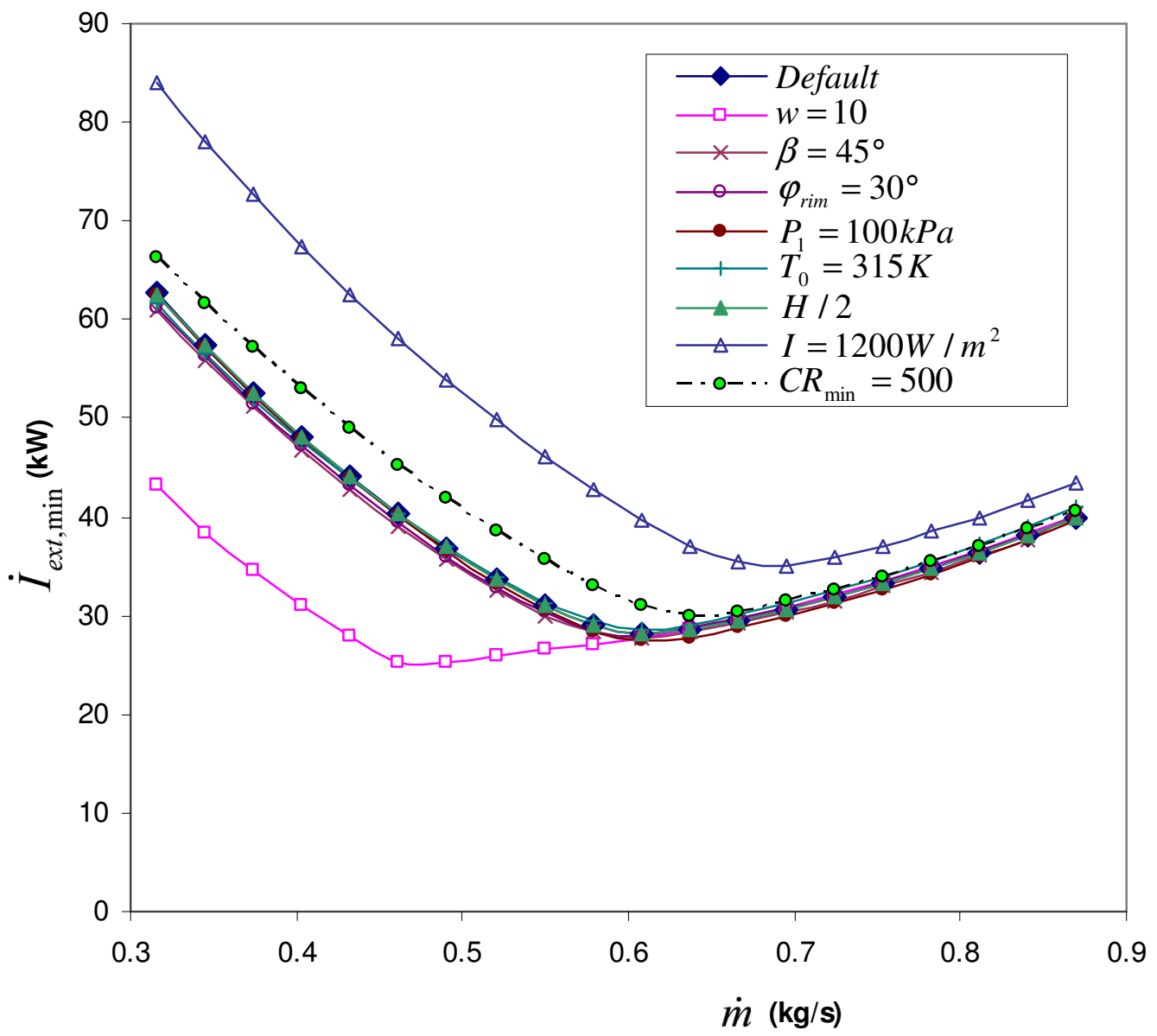

Fig. 14 


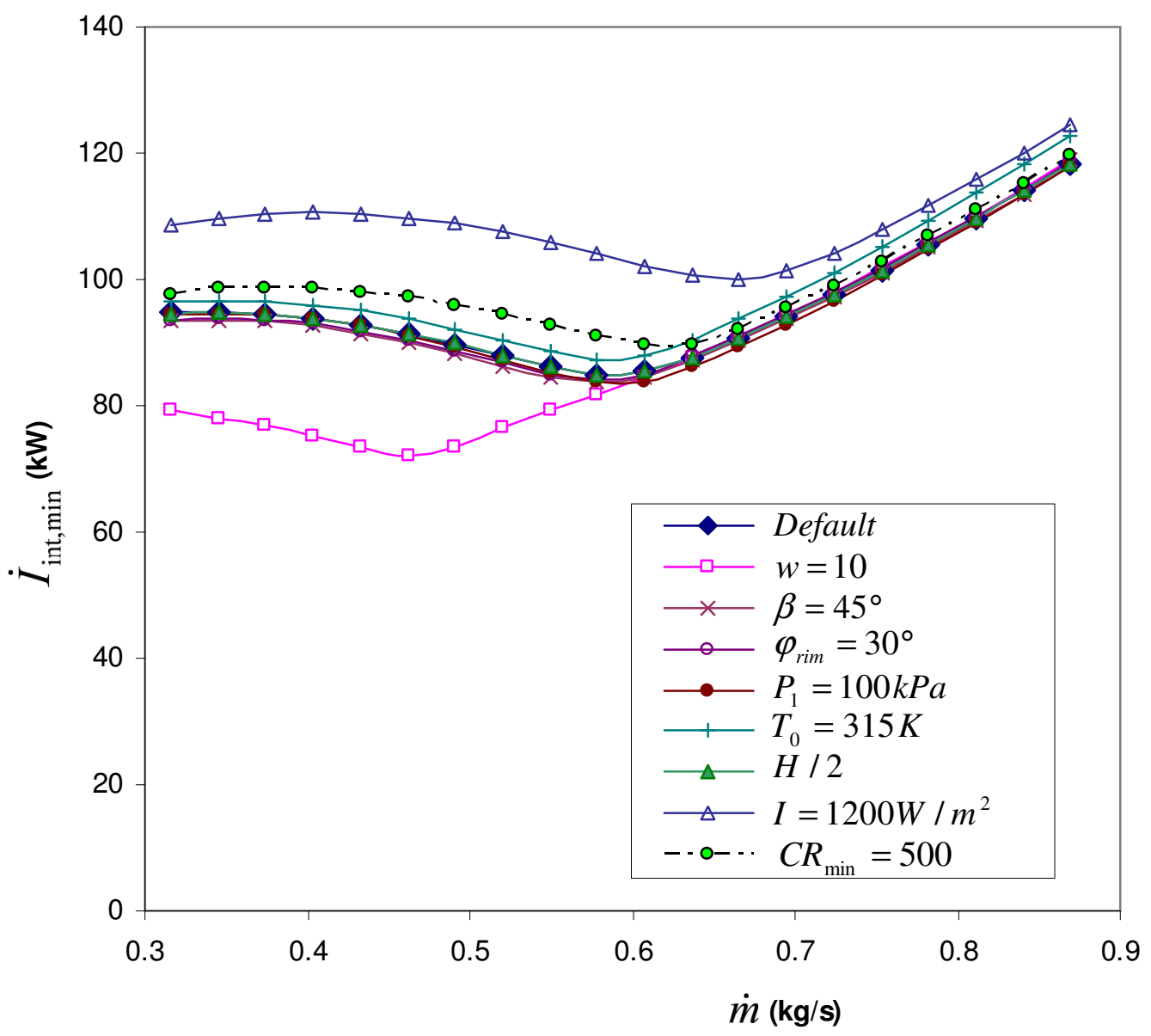

Fig. 15 


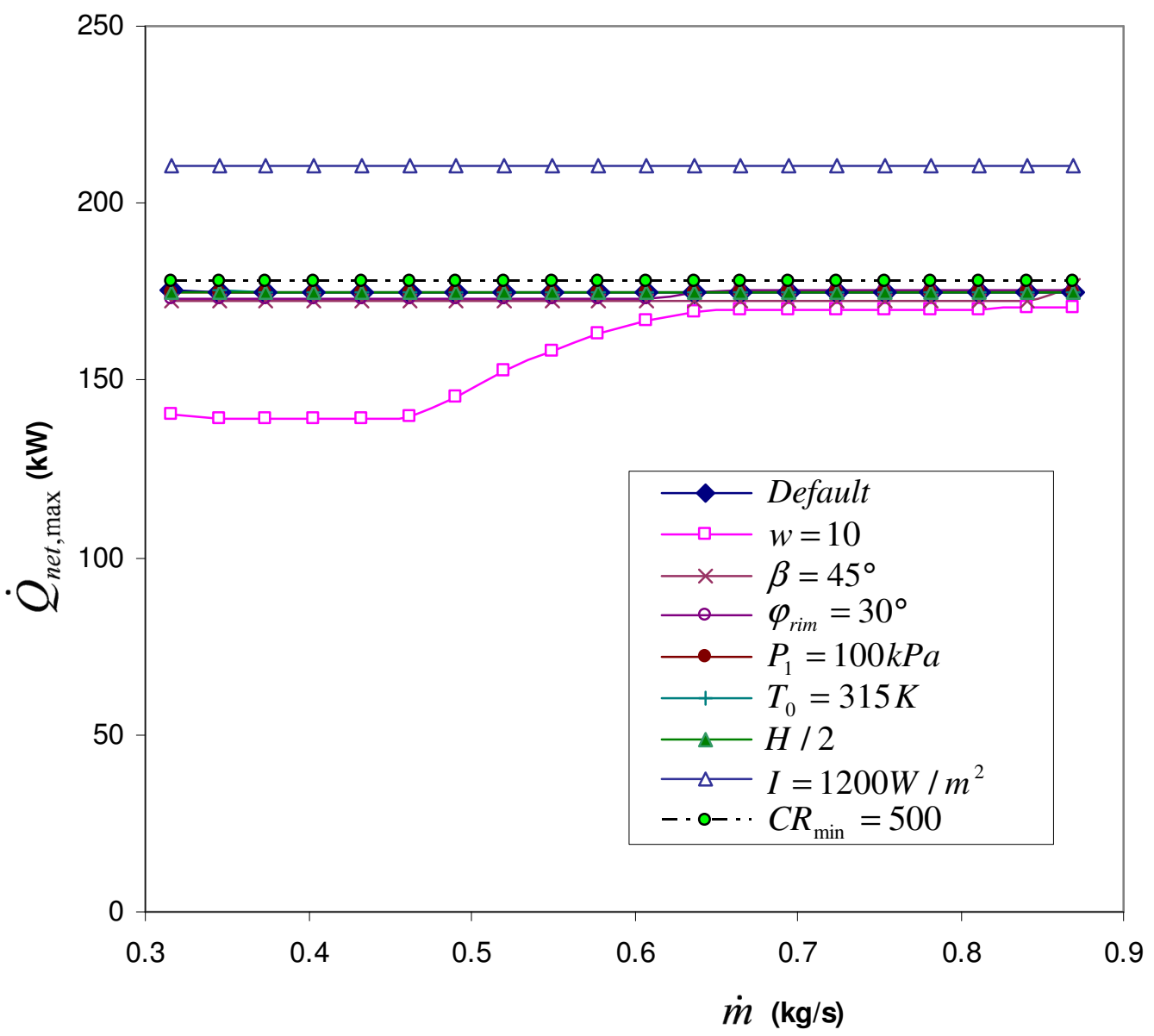

Fig. 16 


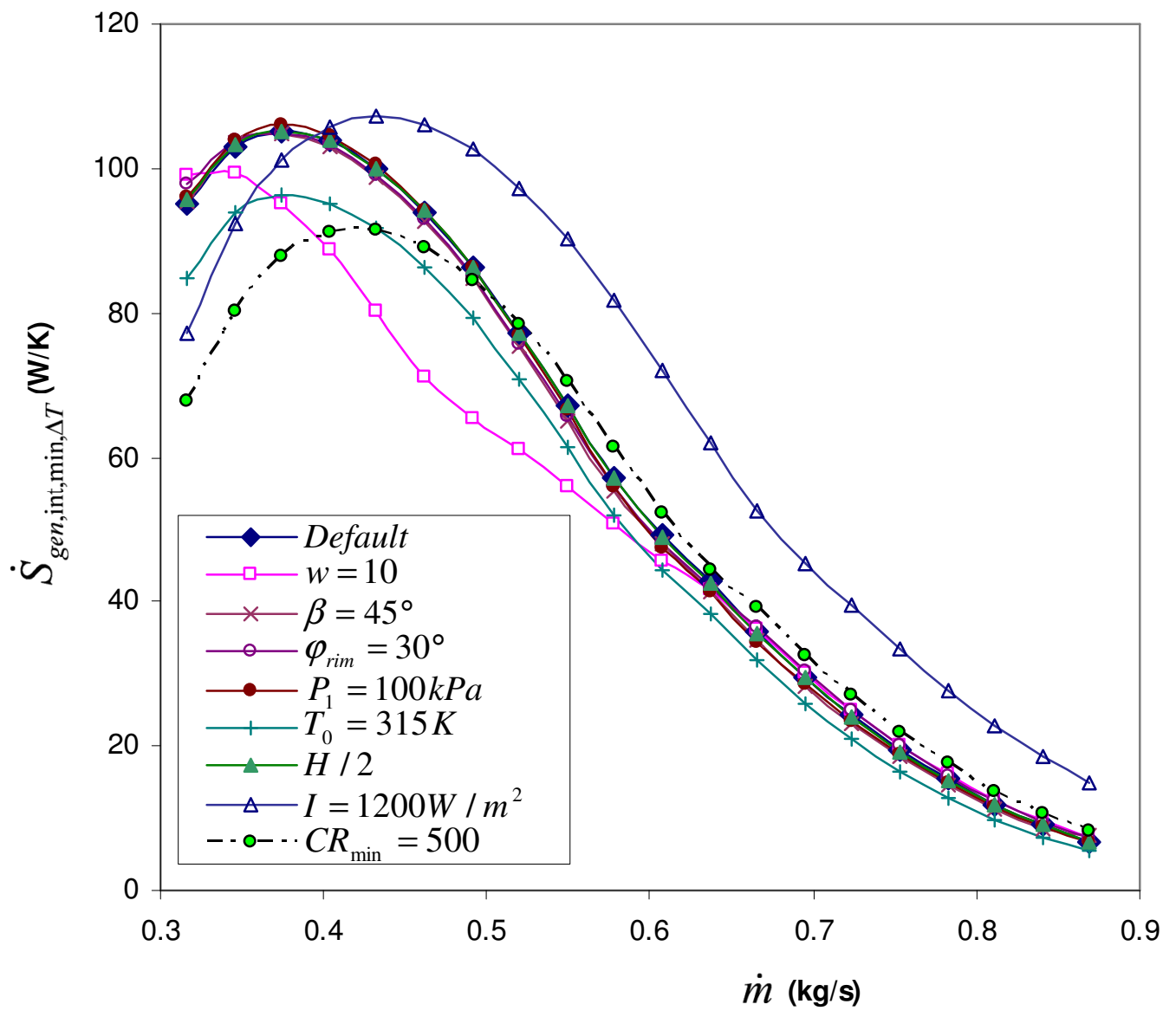

Fig. 17 


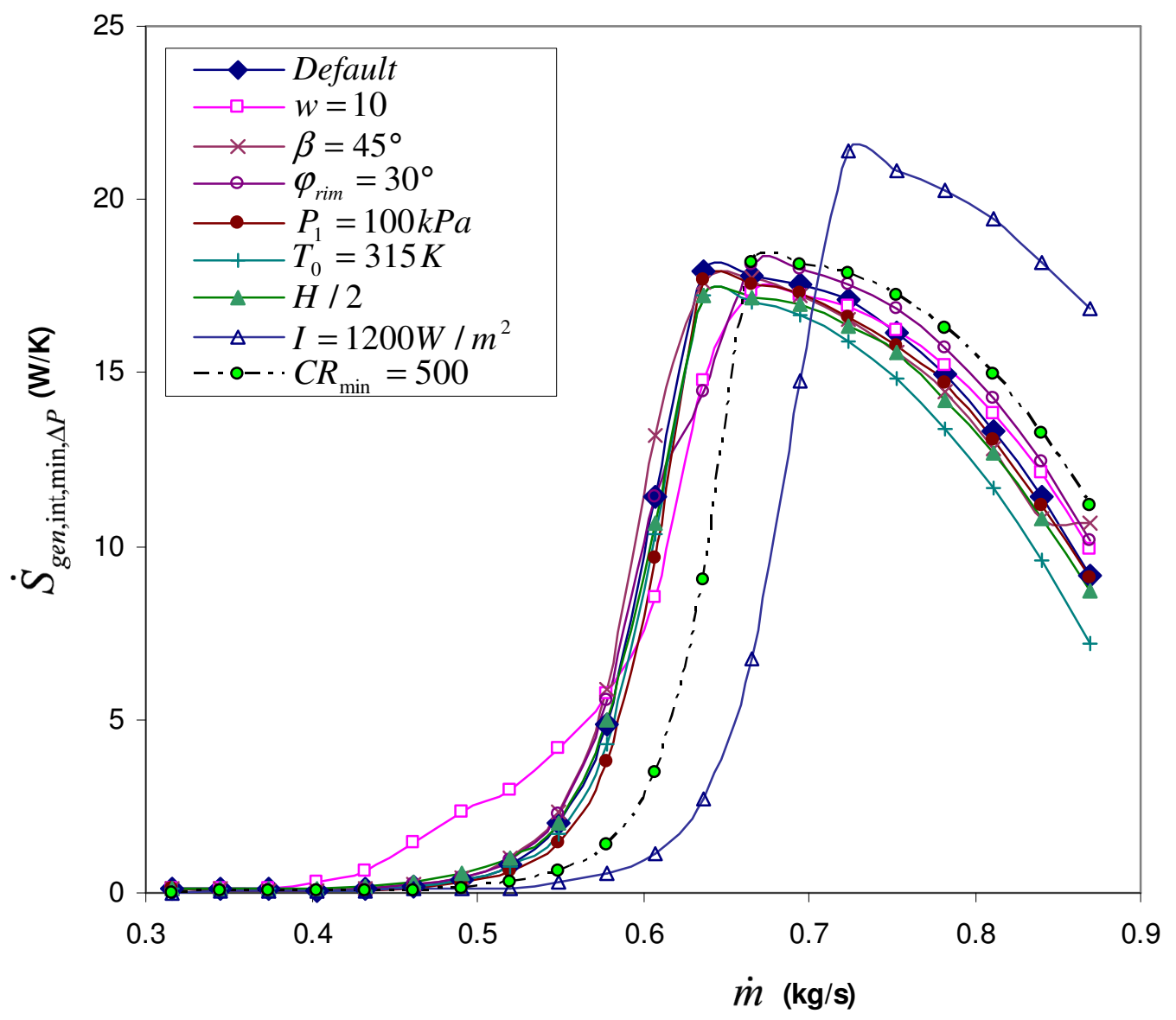

Fig. 18 


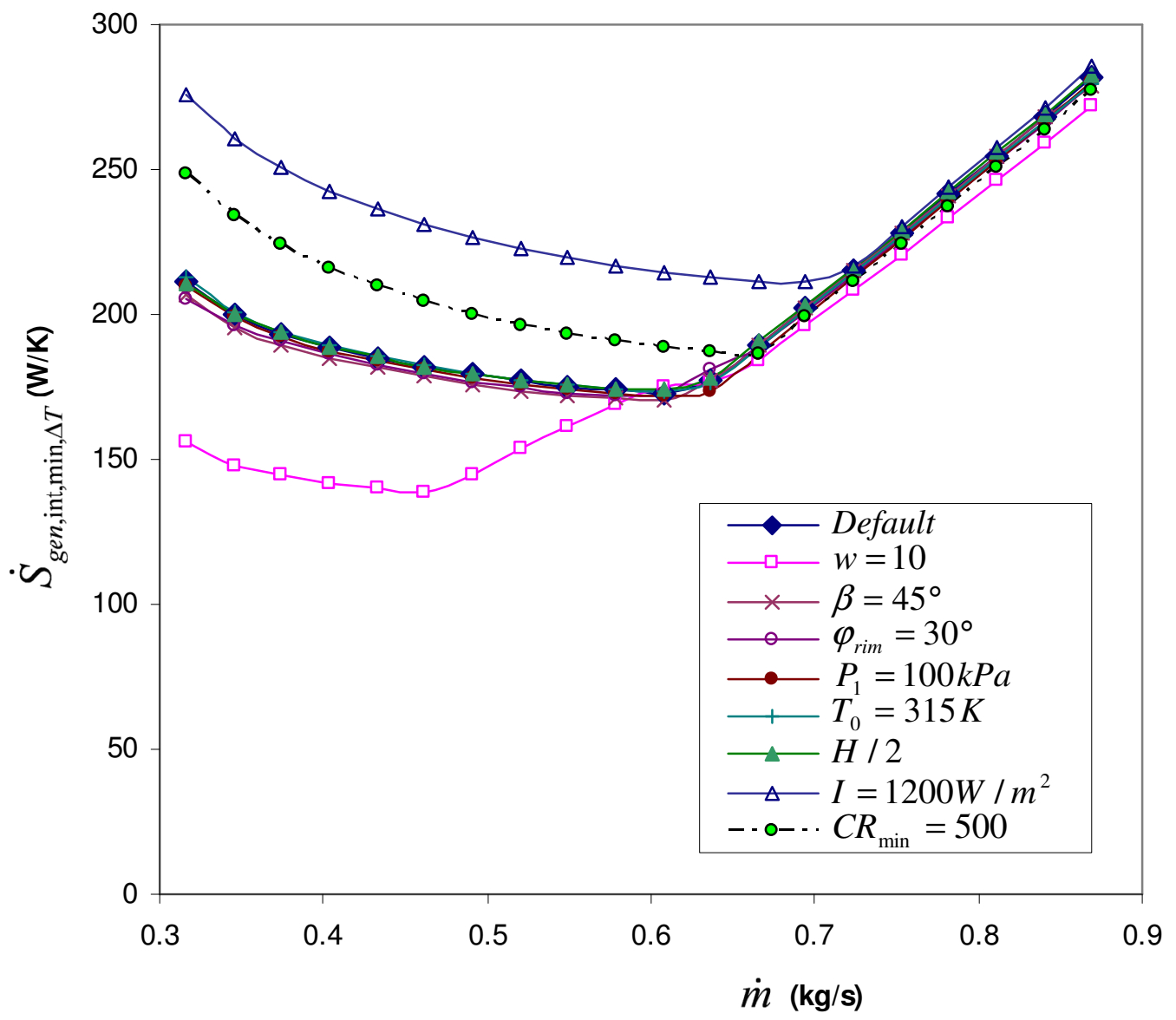

Fig. 19 


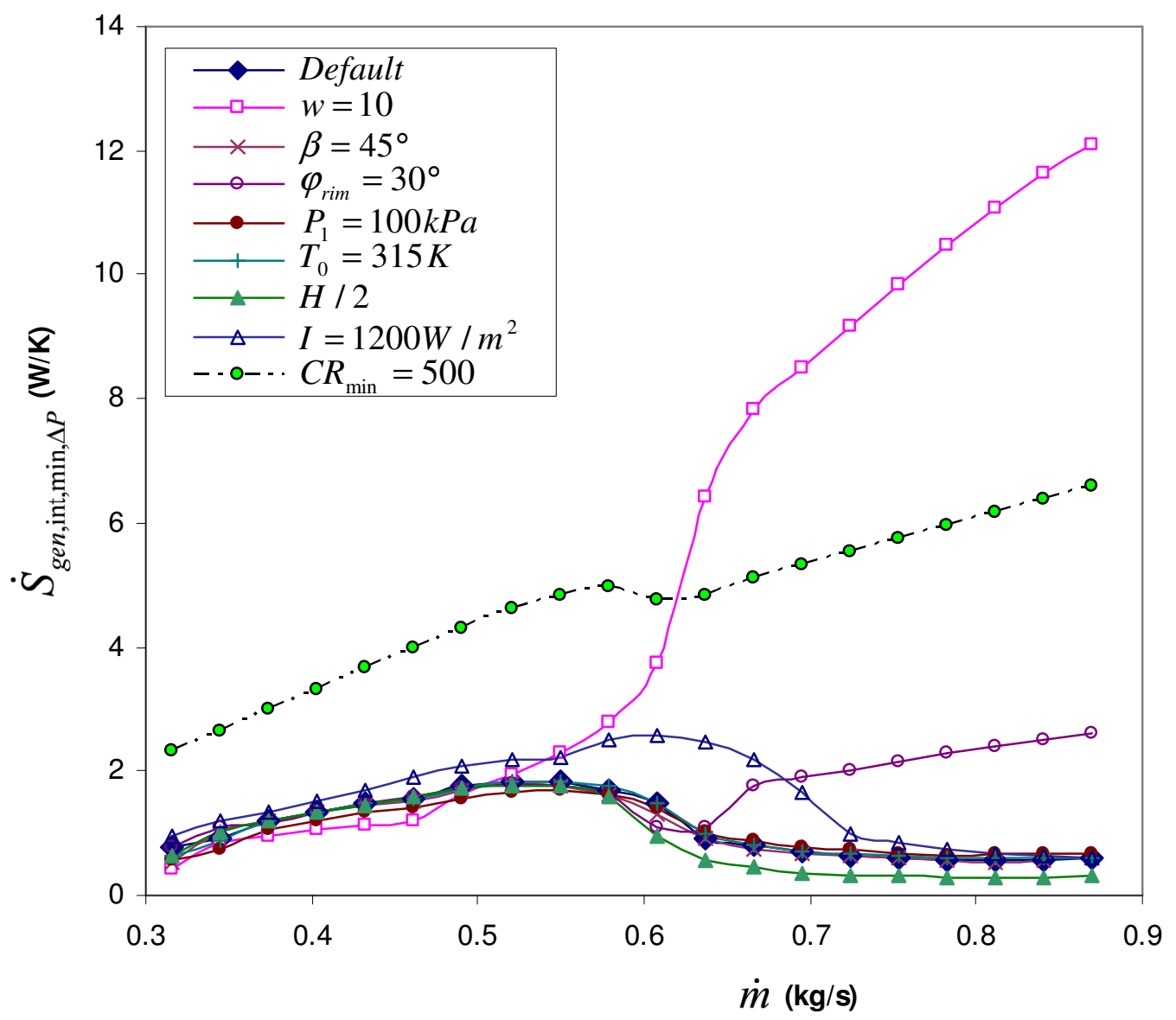

Fig. 20 


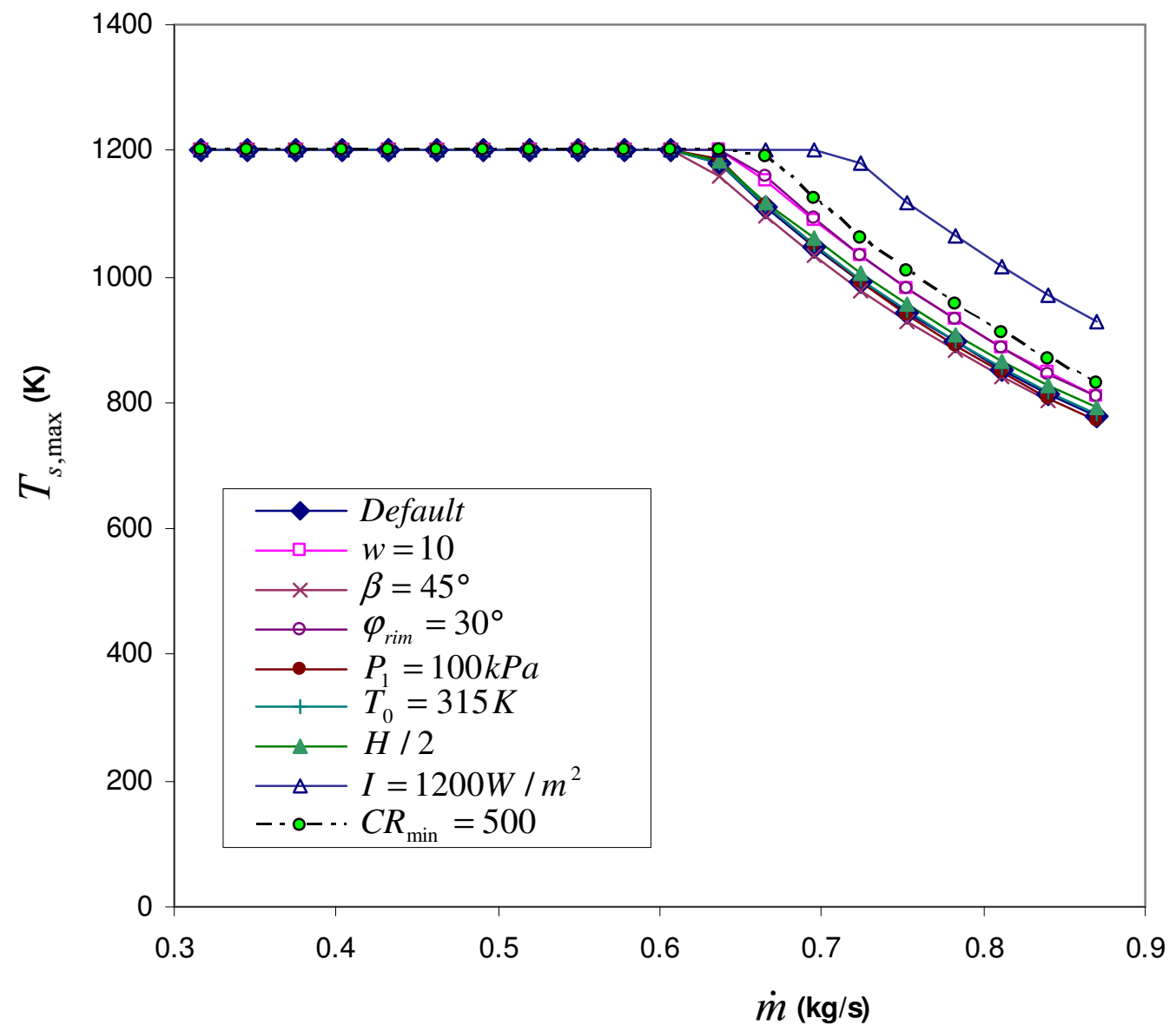

Fig. 21 


\section{Figure captions}

Fig. 1. The open and direct solar thermal Brayton cycle with recuperator.

Fig. 2. Modified cavity receiver.

Fig. 3. Net absorbed heat rate at cavity receiver depending on cavity receiver aperture diameter.

Fig. 4. Counterflow plate-type recuperator.

Fig. 5. Maximum net power output and minimum irreversibility rates.

Fig. 6. Change in maximum net power output due to constants.

Fig. 7. Optimum receiver tube diameter.

Fig. 8. Optimum receiver tube length.

Fig. 9. Optimum recuperator channel aspect ratio.

Fig. 10. Optimum hydraulic diameter of recuperator channels.

Fig. 11. Optimum recuperator length.

Fig. 12. Optimum recuperator channel mass flow rate.

Fig. 13. Optimum recuperator NTU.

Fig. 14. Minimum external irreversibility rate. 
Fig. 15. Minimum internal irreversibility rate.

Fig. 16. Maximum net absorbed heat rate.

Fig. 17. Minimum internal entropy generation rate due to temperature difference in the recuperator.

Fig. 18. Minimum internal entropy generation rate due to pressure difference in the recuperator.

Fig. 19. Minimum internal entropy generation rate due to temperature difference in the receiver.

Fig. 20. Minimum internal entropy generation rate due to pressure difference in the receiver.

Fig. 21. Maximum receiver surface temperature. 


\section{Nomenclature}

\begin{tabular}{|c|c|}
\hline$a$ & Longer side of rectangular recuperator channel, $\mathrm{m}$ \\
\hline$A$ & Area, $\mathrm{m}^{2}$ \\
\hline$b$ & Shorter side of rectangular recuperator channel, $\mathrm{m}$ \\
\hline$c$ & Specific heat, $\mathrm{J} / \mathrm{kgK}$ \\
\hline$C R$ & Concentration ratio $\left(D_{\text {cond }} / d\right)$ \\
\hline$d$ & Receiver aperture diameter, $\mathrm{m}$ \\
\hline$D$ & Diameter, $\mathrm{m}$ \\
\hline$f$ & Friction factor \\
\hline$F$ & Fouling factor \\
\hline$G r$ & Grashof number \\
\hline$h$ & Heat transfer coefficient, $\mathrm{W} / \mathrm{m}^{2} \mathrm{~K}$ \\
\hline$H$ & Recuperator height, $\mathrm{m}$ \\
\hline$I$ & Solar irradiance, $\mathrm{W} / \mathrm{m}^{2}$ \\
\hline$\dot{I}$ & Rate of irreversibility, W \\
\hline$k$ & Thermal conductivity of a fluid, W/mK \\
\hline$L$ & Length, $\mathrm{m}$ \\
\hline$\dot{m}$ & Mass flow rate, $\mathrm{kg} / \mathrm{s}$ \\
\hline$M T$ & Micro-turbine model number $(1-45)$ \\
\hline$n$ & Number of flow channels \\
\hline$N T U$ & Number of transfer units \\
\hline $\mathrm{Nu}$ & Nusselt number \\
\hline$P$ & Pressure, $\mathrm{Pa}$ \\
\hline $\operatorname{Pr}$ & Prandtl number \\
\hline$\dot{Q}$ & Heat transfer rate, $\mathrm{W}$ \\
\hline$\dot{Q}^{*}$ & Rate of intercepted heat at receiver cavity, $\mathrm{W}$ \\
\hline$r$ & Compressor pressure ratio \\
\hline$R$ & Gas constant, $\mathrm{J} / \mathrm{kgK}$ \\
\hline $\operatorname{Re}$ & Reynolds number \\
\hline
\end{tabular}




$\begin{array}{ll}\dot{S} & \text { Entropy rate, W/K } \\ t & \text { Plate thickness between recuperator flow channels, } \mathrm{m} \\ T & \text { Temperature, } \mathrm{K} \\ T^{*} & \text { Apparent sun temperature as an exergy source, } \mathrm{K} \\ V & \text { Velocity, } \mathrm{m} / \mathrm{s} \\ w & \text { Wind factor multiplied with convection heat transfer coefficient } \\ \dot{W} & \text { Power, } \mathrm{W} \\ y & \text { Numerical approximation constant } \\ Z & \text { Height, } \mathrm{m}\end{array}$

Greek symbols:

$\beta \quad$ Inclination angle of receiver

$\varepsilon \quad$ Effectiveness (in the $\varepsilon$-NTU method)

$\varphi \quad$ Concentrator angle

$\mu \quad$ Dynamic viscosity, $\mathrm{kg} / \mathrm{ms}$

$\rho \quad$ Density, $\mathrm{kg} / \mathrm{m}^{3}$

Subscripts:

O Environment

$0 \quad$ Zero-pressure (specific heat)

1,2,3.. Refer to Fig. 1

a Receiver aperture

c Compressor

c Recuperator channel

conc Parabolic dish concentrator

conv Due to convection

D Based on receiver diameter

ext External

gen Generation

$h \quad$ Hydraulic 


\begin{tabular}{ll} 
high & Highest on island of maximum compressor efficiency \\
int & Internal \\
$l$ & Loss to environment \\
loss & Loss from cavity receiver \\
low & Lowest on island of maximum compressor efficiency \\
max & Maximum \\
min & Minimum \\
$n e t$ & Net \\
opt & Optimum \\
$p$ & Constant-pressure (specific heat) \\
$r a d$ & Due to radiation \\
$r e c$ & Receiver tube \\
$r e g$ & Recuperator \\
$r i m$ & Rim \\
$s$ & Surface \\
$s p h$ & Spherical receiver \\
$t$ & Turbine \\
$w$ & Receiver inner wall \\
$\Delta P$ & Due to pressure drop \\
$\Delta T$ & Due to temperature difference \\
& \\
\hline r &
\end{tabular}

